\title{
Impact of the penetration of distributed generation on optimal reactive power dispatch
}

\author{
Tanmay Das ${ }^{1}$, Ranjit Roy ${ }^{2 *}$ and Kamal Krishna Mandal ${ }^{1}$
}

\begin{abstract}
Optimal reactive power dispatch (ORPD) is a complex and non-linear problem, and is one of the sub-problems of optimal power flow (OPF) in a power system. ORPD is formulated as a single-objective problem to minimize the active power loss in a transmission system. In this work, power from distributed generation (DG) is integrated into a conventional power system and the ORPD problem is solved to minimize transmission line power loss. It proves that the application of DG not only contributes to power loss minimization and improvement of system stability but also reduces energy consumption from the conventional sources. A recently proposed meta-heuristic algorithm known as the JAYA algorithm is applied to the standard IEEE 14, 30, 57 and 118 bus systems to solve the newly developed ORPD problem with the incorporation of DG. The simulation results prove the superiority of the JAYA algorithm over others. The respective optimal values of DG power that should be injected into the four IEEE test systems to obtain the minimum transmission line power losses are also provided.
\end{abstract}

Keywords: Active power loss, Distributed generation, DG penetration, JAYA algorithm, Optimization problem, ORPD, Particle swarm optimization, Variants of PSO, Transmission line losses

\section{Introduction}

Minimizing power loss in transmission systems is a major area of research in power system engineering. Voltage collapse, as another major issue, is also attracting much research worldwide to find solutions to improve voltage stability and thus improve the security of the power system and make power transmission more economic. Optimal reactive power dispatch (ORPD) deals with not only the problem of increasing power loss with the expansion of power networks but also the increasing voltage instability problem. The ORPD problem is a sub-problem of optimal power flow (OPF) whose solution helps determine the optimal values to the control variables such as the generator voltage, setting of the tap-changing transformer,

\footnotetext{
* Correspondence: rroy.tigchaibasa@gmail.com

${ }^{2}$ Department of Electrical Engineering, Chaibasa Engineering College,

Chaibasa, Jharkhand, India

Full list of author information is available at the end of the article
}

and the optimal value of reactive power to be injected to compensate for the VAR demand, in order to simultaneously reduce the active power loss and improve voltage stability. Thus, the solution to the ORPD problem helps enhance the security of the power system and improve its economics. However, the ORPD problem is a complex, non-continuous and non-linear problem, and many conventional optimization techniques such as the Newton method, quadratic programming, linear programming, and interior-point methods, have failed to solve it since these methods have low accuracy, high complexity, and inability to find the local and global optima and thus result in insecure convergence [1-6].

Many modern stochastic and meta-heuristic techniques have been applied to overcome these disadvantages, such as the genetic algorithm (GA) [7], improved GA [8], particle swarm optimization (PSO) [9], evolutionary programming (EP) [10], hybrid evolutionary

\section{Springer Open}

(c) The Author(s). 2020 Open Access This article is licensed under a Creative Commons Attribution 4.0 International License, which permits use, sharing, adaptation, distribution and reproduction in any medium or format, as long as you give appropriate credit to the original author(s) and the source, provide a link to the Creative Commons licence, and indicate if changes were made. The images or other third party material in this article are included in the article's Creative Commons licence, unless indicated otherwise in a credit line to the material. If material is not included in the article's Creative Commons licence and your intended use is not permitted by statutory regulation or exceeds the permitted use, you will need to obtain permission directly from the copyright holder. To view a copy of this licence, visit http://creativecommons.org/licenses/by/4.0/. 
strategy [11], the seeker optimization algorithm (SOA) [12], bacterial-foraging optimization (BFO) [13], the gravitational search algorithm (GSA) [14], differential evolution (DE) [15], and the artificial bee colony algorithm (ABC) [16]. K. Medani et al. in [17] applied the whale optimization algorithm which was inspired by the bubble-net hunting technique of the humpback whales to solve the ORPD problem, while A. M. Shaheen et al. in [18] proposed a backtracking search optimizer (BSO) where five diversified generation strategies of mutation factor were applied. In [19], K. Lenin proposed an algorithm named Enhanced Red Wolf Optimization which is a hybrid of the wolf optimization (WO) and particle swarm optimization (PSO) algorithm, to solve the ORPD problem. In [20], an improved social spider optimization (ISSO) was used for determining the optimal solution of power loss in the ORPD problem. Zelan Li et al. [21] proposed an Antlion optimization algorithm (IALO) for a three-bus system, whereas R. N. S Mei et al. [22] used two different algorithms, namely the Moth-Flame Optimizer and Ant Lion Optimizer, to optimize the ORPD problem.

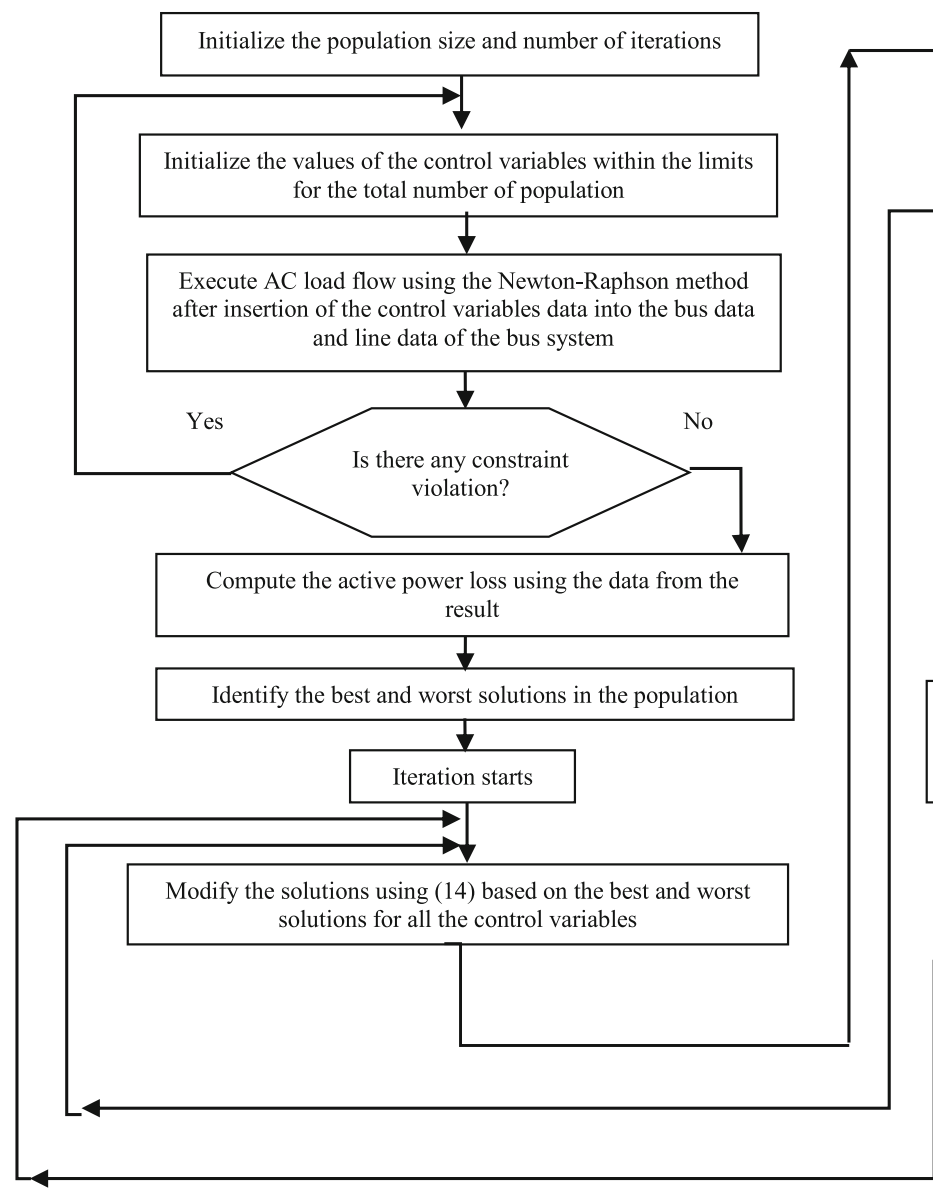

This paper uses a novel algorithm, namely the JAYA algorithm developed by Rao [23], to solve the ORPD problem. Many other algorithms such as PSO and different variants of PSO, e.g., R-PSO, L-PSO, PSO-CFA, Improved PSO Based on Success Rate (IPSO-SR) [24], Fruit Fly optimization algorithm (FOA), and modified Fruit Fly optimization algorithm (MFOA) are also tested along with the JAYA algorithm. The results are compared to determine the best algorithm in terms of convergence, the ability to determine the optimal solution, and robustness.

The main contributions of the paper are as follows:

i) Minimizing transmission line power loss by obtaining the optimal setting of the control variables within the system without violating the equality and inequality constraints.

ii) Incorporating the concept of distributed generation (DG) into the ORPD problem to study its effect and analyze its contribution towards minimizing power loss and increasing system efficiency in the problem.

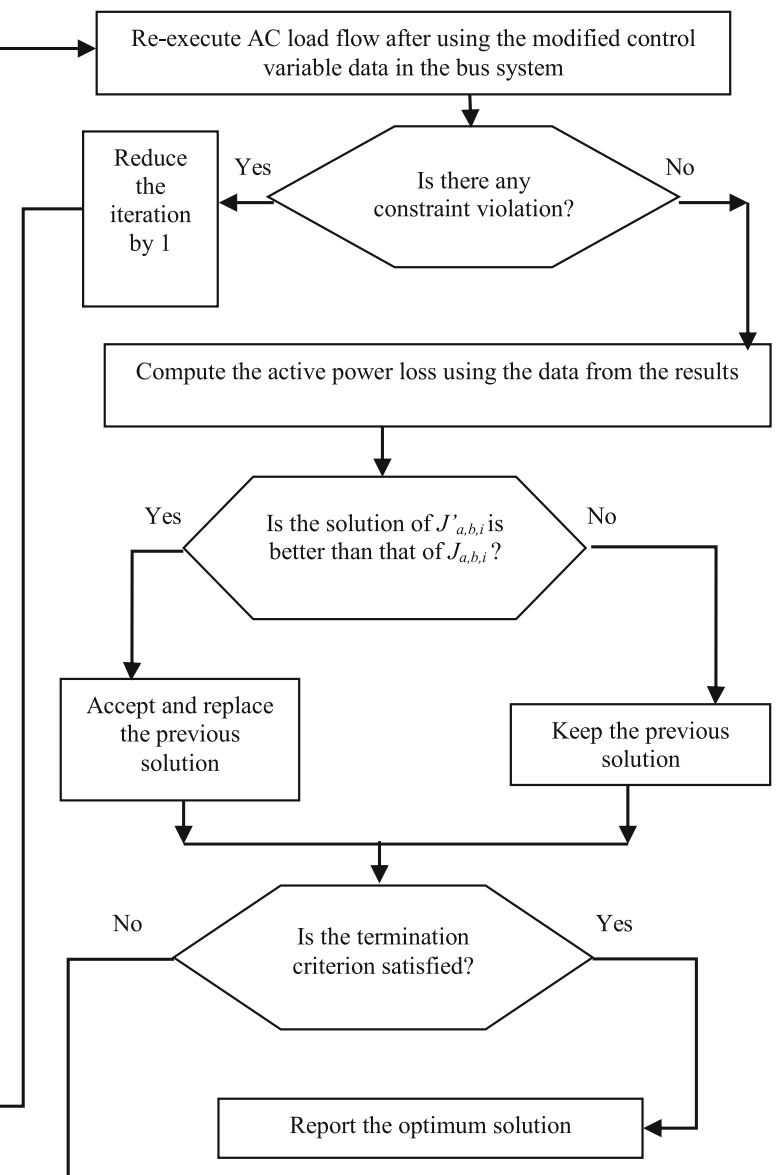

Fig. 1 Flow chart of the JAYA algorithm implemented on the ORPD problem 


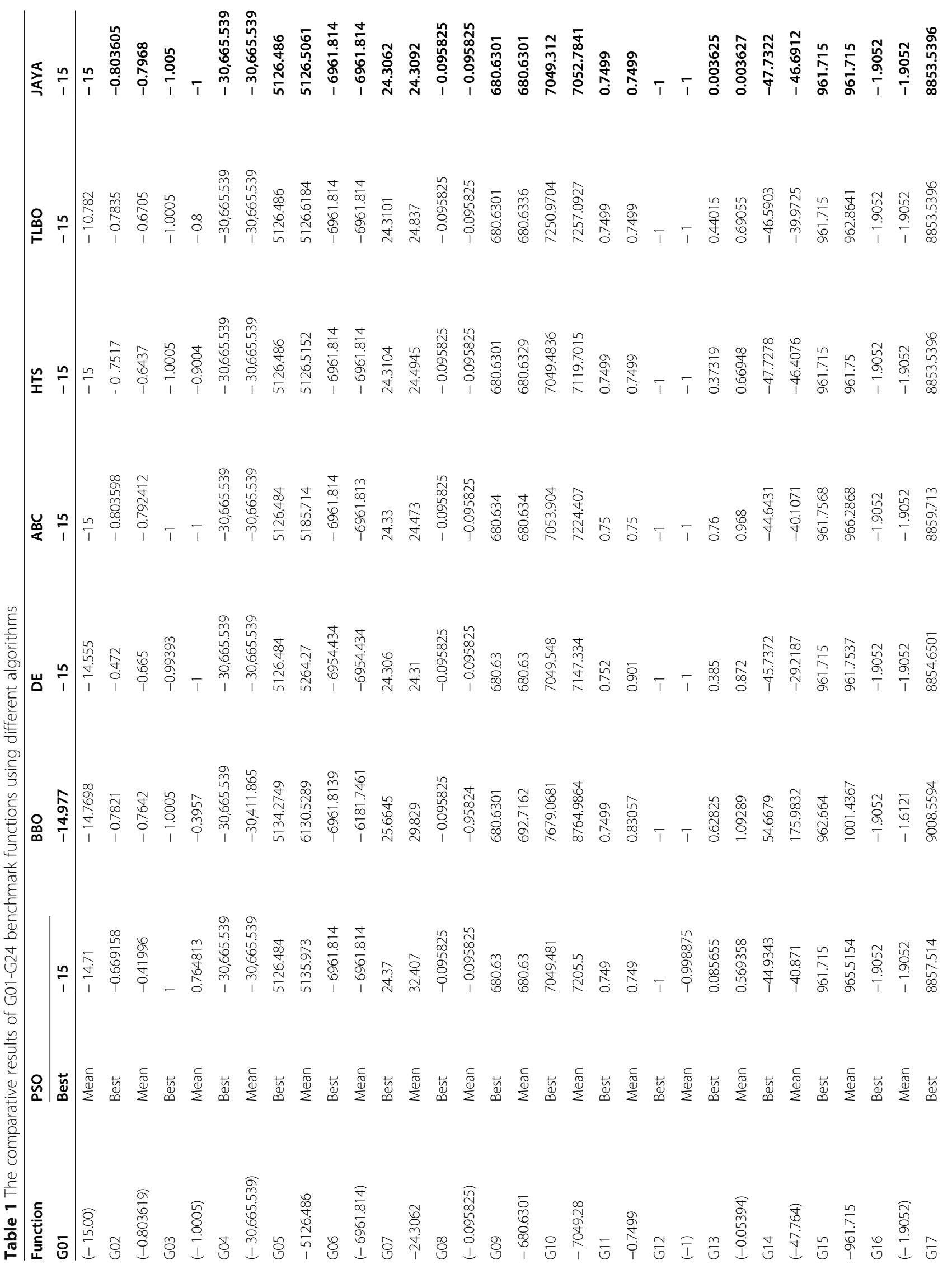




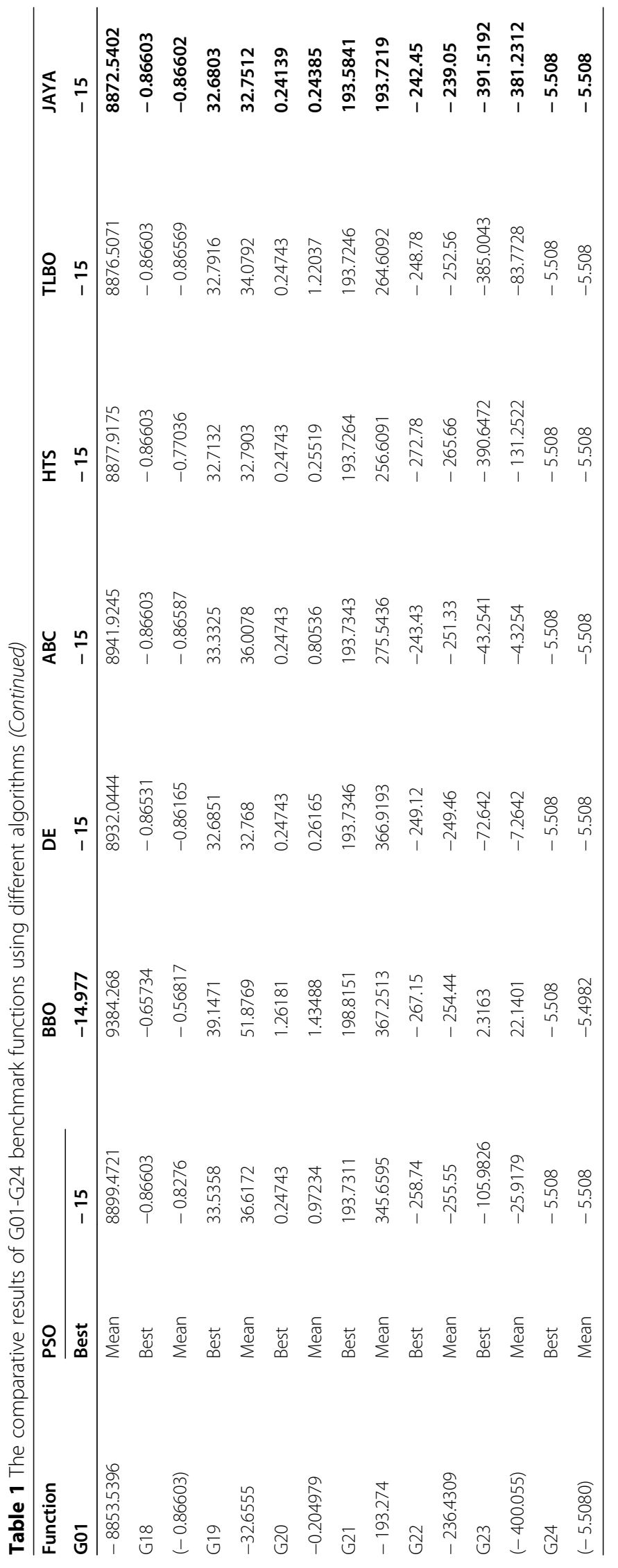


Table 2 Typical parameters of the bus systems

\begin{tabular}{lllll}
\hline Control variables & IEEE $\mathbf{1 4}$ bus system & IEEE $\mathbf{3 0}$ bus system & IEEE $\mathbf{5 7}$ bus system & IEEE $\mathbf{1 1 8}$ bus system \\
\hline Buses & 14 & 30 & 57 & 118 \\
Generators & 5 & 6 & 7 & 54 \\
Transformers & 3 & 4 & 15 & 9 \\
Shunt compensators & 2 & 3 & 3 & 14 \\
Transmission lines & 20 & 41 & 80 & 186 \\
Control variables & 10 & 13 & 25 & 77 \\
Base Ploss (MW) & 13.49 & 5.66 & 27.8637 & 132.45 \\
\hline
\end{tabular}

iii) The superiority of the JAYA algorithm is established over other algorithms reported in the literature.

\subsection{Distributed generation}

Alternative sources of energy such as wind, solar, etc. are being used currently. In many cases, such sources of energy are used to generate power on a small scale in areas close to the end users. The end users consume power and any excess power is sent back to the grid. This approach is called distributed generation (DG) and it helps reduce coal consumption, the cost of generation, and transmission line power loss. Furthermore, the demand of consumers in remote areas can be fulfilled from the local generation and the risk of voltage collapse is also reduced. Much research has been carried out to increase the utilization of DG to enhance the security and economic growth of power systems [25-30].

In this work, DG power is supplied to the buses along with power from conventional sources to study the transmission line loss characteristic by solving the ORPD problem. The DG power is injected individually at each bus (except for the slack bus) within a specified limit and the ORPD problem is solved to determine the optimal values of the control variables for minimizing transmission line losses. The control variables chosen for the ORPD problem are the

Table 3 Simulation results on the IEEE 14 bus system using different algorithms without DG injection

\begin{tabular}{|c|c|c|c|c|c|c|c|c|}
\hline Control Variables (p.u.) & PSO & R-PSO & L-PSO & PSO-CFA & IPSO-SR & FOA & MFOA & JAYA \\
\hline$\overline{V_{G 1}}$ & 1.1 & 1.1 & 1.1 & 1.1 & 1.1 & 1.1 & 1.1 & 1.1 \\
\hline$V_{G 2}$ & 1.1 & 1.1 & 1.1 & 1.1 & 1.0863 & 1.1 & 1.1 & 1.0859 \\
\hline$V_{G 3}$ & 1.0701 & 1.0696 & 1.0703 & 1.0702 & 1.0578 & 1.1 & 1.1 & 1.0568 \\
\hline$V_{G 6}$ & 1.1 & 1.1 & 1.1 & 1.0605 & 1.0575 & 0.9 & 1.1 & 1.1 \\
\hline$V_{G 8}$ & 1.1 & 1.1 & 1.1 & 1.1 & 1.0726 & 0.95 & 1.1 & 1.1 \\
\hline $\mathrm{T}_{4-7}$ & 0.9285 & 0.9551 & 1.1 & 1.1 & 0.9685 & 1.1 & 1.1 & 0.9492 \\
\hline $\mathrm{T}_{4-9}$ & 1.1 & 1.1 & 0.9 & 0.9 & 1.1 & 0.935 & 1.1 & 1.0766 \\
\hline$T_{5-6}$ & 1.1 & 1.0179 & 1.0047 & 1.1 & 1.1 & 1.1 & 1.1 & 1.0031 \\
\hline $\mathrm{Q}_{\mathrm{sc9}}$ & 0.2332 & 0.3 & 0.2643 & 0.015 & 0.2134 & 0.000328 & 0.0443 & 0.3 \\
\hline $\mathrm{Q}_{\mathrm{sc14}}$ & 0.0555 & 0.0604 & 0.0 & 0.0641 & 0.0634 & 0.000296 & 0.0443 & 0.0594 \\
\hline Total $P_{\text {loss }}(\mathrm{MW})$ & 12.4268 & 12.3585 & 12.4041 & 12.416 & 12.2957 & 12.5992 & 12.7531 & 12.2270 \\
\hline DE [32] & $\mathrm{ABC}[32]$ & $\mathrm{ACO}_{\mathrm{R}}[32]$ & TLA [32] & DE [32] & MTLA [32] & MTLA-DDE [32] & LCA [32] & CSS [32] \\
\hline 13.1053 & 12.9333 & 13.1226 & 12.9229 & 13.1053 & 12.9106 & 12.8978 & 12.9891 & 12.9748 \\
\hline BRCFF [32] & $\mathrm{BB}-\mathrm{BC}[32]$ & PBIL [32] & DDE [32] & TLBO [33] & BBPSO [33] & BBDE [33] & GBTLBO [33] & MGBTLBO [33] \\
\hline 12.9264 & 13.0039 & 13.0008 & 12.9286 & 12.9878 & 12.9919 & 12.9973 & 12.4152 & 12.3105 \\
\hline PSO [17] & PSO-TVAC [17] & WOA [17] & MDE [18] & SARGA [18] & RTS [18] & EP [18] & BSO 1 [18] & BSO 2 [18] \\
\hline 12.381 & 12.279 & 12.255 & 13.0532 & 13.21643 & 13.236 & 13.3462 & 12.4633 & 12.4672 \\
\hline BSO 3 [18] & BSO 4 [18] & BSO 4 [18] & & & & & & \\
\hline 12.4651 & 12.4588 & 12.4699 & & & & & & \\
\hline
\end{tabular}




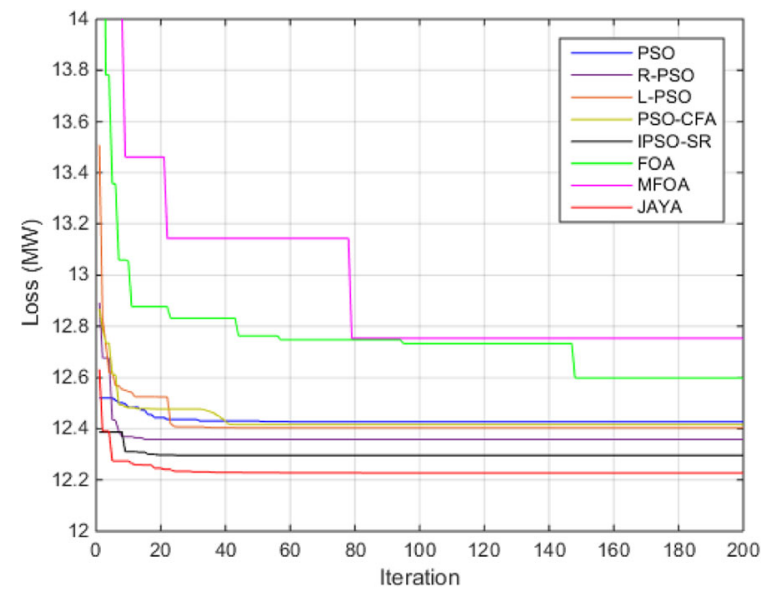

Fig. 2 Convergence characteristics of the algorithms for the IEEE 14 bus system without DG injection

generator bus voltages, tap position of the tapchanging transformer, the VAR output of the compensating devices, and the injected DG active power. Thus for an n-bus system, the ORPD problem is solved n-1 times. The proposed algorithm is used to determine the optimal value of DG power for each bus in order to reduce transmission line loss for the ORPD problem. The power losses for the $n-1$ buses are compared, and the bus with the minimum power loss and the corresponding injected DG power are selected.

\section{Problem formulation}

The objective of solving the ORPD problem is the minimization of power loss in transmission lines incorporating DG. The solution to this problem is to determine the optimal values of the control variables while simultaneously satisfying all the constraints in the system. First, the ORPD problem is solved without the incorporation of DG in the system, and power losses for the test cases are evaluated and compared using different optimization algorithms. The DG is then introduced and the algorithms again determine the power loss of the system with the penetration of DG. The objective function remains the same while the amount of DG power to be injected is considered as an additional control variable.

The objective function for the problem is expressed as [4]:

$$
f_{\mathrm{n}}=\min \left(P_{\mathrm{loss}}\right)=\sum_{k=1}^{N l} G_{k}\left(V_{i}^{2}+V_{j}^{2}-2 V_{i} V_{j} \cos \delta_{i j}\right)
$$

where $\mathrm{Nl}$ represents the total number of transmission lines, and the conductance of the $k^{\text {th }}$ branch is $G_{k}$. $V_{i}$ and $V_{j}$ represent the magnitudes of the bus voltage for buses $i$ and $j$, respectively, and $\delta_{i j}$ is the phase difference between $V_{i}$ and $V_{j}$. The different constraint

Table 4 Simulation results on the IEEE 30 bus system using different algorithms without DG injection

\begin{tabular}{|c|c|c|c|c|c|c|c|c|}
\hline Control Variables (p.u.) & PSO & R-PSO & L-PSO & PSO-CFA & IPSO-SR & FOA & MFOA & JAYA \\
\hline$V_{G 1}$ & 1.1 & 1.1 & 1.1 & 1.1 & 1.1 & 0.9757 & 0.95 & 1.1 \\
\hline$V_{G 2}$ & 1.1 & 1.1 & 1.1 & 1.1 & 1.1 & 0.95 & 0.95 & 1.0945 \\
\hline$V_{G 5}$ & 1.1 & 1.1 & 1.1 & 1.0806 & 1.1 & 0.95 & 0.95 & 1.0752 \\
\hline$V_{G 8}$ & 1.1 & 1.1 & 1.1 & 1.0821 & 1.0882 & 0.95 & 0.95 & 1.077 \\
\hline$V_{G 11}$ & 1.1 & 1.1 & 1.1 & 1.1000 & 1.1 & 1.1 & 0.95 & 1.1 \\
\hline$V_{G 13}$ & 1.1 & 1.1 & 1.1 & 1.1000 & 1.1 & 1.1 & 0.95 & 1.1 \\
\hline $\mathrm{T}_{6-9}$ & 0.9981 & 1.1 & 1.1 & 0.9777 & 0.9758 & 0.9 & 0.9 & 1.073 \\
\hline$T_{6-10}$ & 1.1 & 0.9 & 1.1 & 1.1 & 1.1 & 0.9 & 0.9 & 0.9001 \\
\hline$T_{4-12}$ & 0.9726 & 0.9729 & 1.0063 & 1.1 & 0.9553 & 0.9 & 0.9 & 0.9411 \\
\hline $\mathrm{T}_{28-27}$ & 0.9896 & 0.9746 & 0.998 & 1.0041 & 0.9644 & 0.9 & 0.9 & 0.9522 \\
\hline $\mathrm{Q}_{\mathrm{sC3}}$ & 0.0 & 0.0 & 0.0 & 0.0 & 0.094958 & 0.0003 & 0.2993 & 0.0915 \\
\hline$Q_{\text {sc10 }}$ & 0.36 & 0.2362 & 0.36 & 0.0954 & 0.36 & 0.0005 & 0.2993 & 0.2824 \\
\hline $\mathrm{Q}_{\mathrm{sc24}}$ & 0.0949 & 10.056 & 0.1032 & 0.107 & 0.0994 & 0.0003 & 0.2993 & 0.0978 \\
\hline$P_{\text {loss }}(\mathrm{MW})$ & 4.7915 & 4.7392 & 4.8655 & 4.7282 & 4.7190 & 6.2775 & 5.0957 & 4.5983 \\
\hline ICA [34] & IWO [34] & MICA-IWO [34] & C-PSO [35] & Cl-PSO [35] & LDI-PSO [35] & B-DE [35] & R-DE [35] & SFLA [35] \\
\hline 4.6155 & 4.6287 & 4.5984 & 4.6801 & 4.6124 & 4.6124 & 4.6124 & 4.6675 & 4.6148 \\
\hline \multicolumn{9}{|l|}{ NMSFLA [35] } \\
\hline 4.6118 & & & & & & & & \\
\hline
\end{tabular}




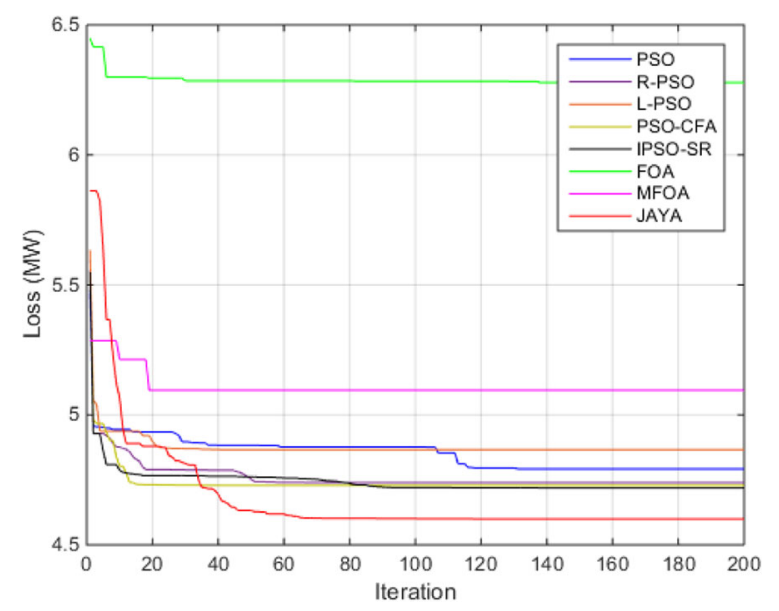

Fig. 3 Convergence characteristics of the algorithms for the IEEE 30 bus system without DG injection

that need to be satisfied are discussed in the following sub-sections.

\subsection{Constraints}

The constraints are mainly categorized into equality constraints and inequality constraints as follows:

\subsubsection{Equality constraints}

These constraints depict the load flow equations as:

$$
\begin{aligned}
& P_{g i}-P_{d i}-V_{i} \sum_{j=1}^{N b} V_{j}\left(G_{i j} \cos \delta_{i j}+B_{i j} \sin \delta_{i j}\right)=0 \\
& Q_{g i}-Q_{d i}-V_{i} \sum_{j=1}^{N b} V_{j}\left(G_{i j} \cos \delta_{i j}+B_{i j} \sin \delta_{i j}\right)=0
\end{aligned}
$$

where the total number of buses is $N b, P_{g i}$ and $Q_{g i}$ represent the active and reactive power generation, and $P_{d i}$ and $Q_{d i}$ are the active and reactive power load demands for the $i^{t h}$ bus, respectively. $G_{i j}$ and $B_{i j}$ represent the conductance and susceptance between the $i^{\text {th }}$ and $j^{\text {th }}$ buses, respectively.

\subsubsection{Inequality constraints}

\section{- Generator constraints:}

The active and reactive power generation of the generator and its voltage magnitude are all set within their limits when solving the problem, as:

$$
\begin{aligned}
V_{\mathrm{gi}}^{\min } \leq V_{g i} \leq V_{g i}^{\max }, & i=1, \ldots, N_{g} \\
P_{g i}^{\min } \leq P_{g i} \leq P_{g i}^{\max }, & i=1, \ldots \ldots \ldots \ldots, N_{g} \\
Q_{g i}^{\min } \leq Q_{g i} \leq Q_{g i}^{\max }, & i=1, \ldots \ldots \ldots \ldots, N_{g}
\end{aligned}
$$

Table 5 Statistical analysis for case 2 of the IEEE 30 bus system

\begin{tabular}{lllllll}
\hline Algorithm & Best (MW) & Worst (MW) & Mean (p.u.) & Standard deviation (std.) & \% of Power save & Average computation time (s) \\
\hline C-PSO [34] & 4.68017 & 5.69149 & 5.14339 & $2.8854 \times 10^{-3}$ & 17.3114 & 45.67 \\
CI-PSO [34] & 4.61244 & 4.87635 & 4.64732 & $5.834 \times 10^{-4}$ & 18.5081 & 56.76 \\
LDI-PSO [34] & 4.61243 & 4.93822 & 4.62908 & $4.851 \times 10^{-4}$ & 18.5083 & 49.57 \\
B-DE [34] & 4.61243 & 4.61333 & 4.61281 & $2.6 \times 10^{-6}$ & 18.5083 & 46.78 \\
R-DE [34] & 4.66755 & 4.98274 & 4.75088 & $6.54 \times 10^{-4}$ & 17.5344 & 54.07 \\
SFLA [34] & 4.61483 & 4.97653 & 4.72213 & $9.973 \times 10^{-4}$ & 18.4659 & 41.97 \\
NMSFLA [34] & 4.61181 & 4.61749 & 4.61264 & $9.8 \times 10^{-6}$ & 18.5192 & 23.06 \\
ICA [34] & 4.6155 & 4.6624 & 4.6397 & $2.7613 \times 10^{-3}$ & 18.4541 & 68.14 \\
IWO [34] & 4.6287 & 4.9206 & 4.7813 & $3.1584 \times 10^{-2}$ & 18.2208 & 70.45 \\
MICA-IWO [34] & 4.5984 & 4.6009 & 4.5991 & $8.006 \times 10^{-6}$ & 18.7562 & 69.04 \\
PSO & 4.7915 & 4.9387 & 4.9053 & $9.08 \times 10^{-3}$ & 15.3445 & 50.73 \\
R-PSO & 4.7392 & 5.0006 & 4.8695 & $8.707 \times 10^{-3}$ & 16.2686 & 50.75 \\
L-PSO & 4.8655 & 5.0222 & 4.9496 & $5.1176 \times 10^{-3}$ & 14.0371 & 48.53 \\
PSO-CFA & 4.7282 & 4.9185 & 4.8334 & $6.668 \times 10^{-3}$ & 16.4629 & 50.63 \\
IPSO-SR & 4.719 & 4.9316 & 4.84455 & $6.668 \times 10^{-3}$ & 16.6254 & 51.13 \\
FOA & 6.2775 & 6.3832 & 6.3605 & $5.3887 \times 10^{-3}$ & -10.9099 & 49.28 \\
MFOA & 5.0957 & 5.1424 & 5.13425 & $1.724 \times 10^{-3}$ & 9.97 & 52.79 \\
JAYA & 4.5983 & 4.5986 & 4.5984 & $9.4281 \times 10^{-5}$ & 18.7579 & 50.44 \\
\hline
\end{tabular}


Table 6 Frequency of convergence for the IEEE 30 bus system case 2 in 50 trial runs

\begin{tabular}{lllllllll}
\hline Algorithms & $\mathbf{4 . 5 9 - 4 . 6 0}$ & $\mathbf{4 . 6 1 - 4 . 7 0}$ & $\mathbf{4 . 7 1 - 4 . 8 0}$ & $\mathbf{4 . 8 1 - 4 . 9 0}$ & $\mathbf{4 . 9 1 - 5 . 0}$ & $\mathbf{5 . 0 1 - 5 . 1 0}$ & $\mathbf{5 . 1 1 - 5 . 2 0}$ & $\mathbf{7} \mathbf{6 . 0 1}$ \\
\hline PSO & 0 & 0 & 1 & 30 & 19 & 0 & 0 & 0 \\
R-PSO & 0 & 0 & 11 & 33 & 6 & 0 & 0 & 0 \\
L-PSO & 0 & 0 & 3 & 25 & 22 & 0 & 0 \\
PSO-CFA & 0 & 0 & 18 & 27 & 5 & 0 & 0 & 0 \\
IPSO-SR & 0 & 0 & 4 & 0 & 0 & 0 & 0 \\
FOA & 0 & 0 & 0 & 0 & 0 & 0 & 0 \\
MFOA & 0 & 0 & 0 & 0 & 0 & 0 & 0 & 0 \\
JAYA & 50 & 0 & 0 & 0 & 0 & 0 \\
\hline
\end{tabular}

where, $N_{g}$ represents the total number of generator buses, $V_{g i}^{\text {min }}, P_{g i}^{\text {min }}$ and $Q_{g i}^{\min }$ are the minimum limits and $V_{g i}^{m a x}, P_{g i}^{m a x}$ and $Q_{g i}^{m a x}$ are the maximum limits of the generator bus voltages, active and reactive power, respectively. $V_{g i}, P_{g i}$ and $Q_{g i}$ are the voltage, active and reactive power generation at the $i^{\text {th }}$ bus, respectively.

\section{- Transformer constraints:}

$$
T_{i}^{\min } \leq T_{i} \leq T_{i}^{\max }, \quad i=1, \ldots, N_{T}
$$

- VAR compensator constraints:

$$
Q_{c i}^{\min } \leq Q_{c i} \leq Q_{c i}^{\max }, \quad i=1, \ldots \ldots \ldots \ldots, N_{C}
$$

- Operating constraints:

$$
\begin{aligned}
& V_{L i}^{\min } \leq V_{L i} \leq V_{L i}^{\max }, \quad i=1, \ldots \ldots \ldots \ldots, N_{P Q} \\
& S_{L i} \leq S_{L i}^{\max }, \quad i=1, \ldots \ldots \ldots \ldots, N L
\end{aligned}
$$

Equation 7 shows the maximum and minimum limits of the tap changing transformers, where $N_{T}$ represents the number of tap-changing transformers in the system, $T_{i}$ is the transformer tap-setting

Table 7 Control variable limits (p.u.) for the test cases

\begin{tabular}{llllll}
\hline \multicolumn{6}{l}{ Limits of voltages and tap settings (p.u.) } \\
\hline $\mathbf{V}_{\mathbf{g}}^{\min }$ & $\mathbf{V}_{\mathbf{g}}^{\max }$ & $\mathbf{V}_{\mathrm{PQ}}^{\min }$ & $\mathbf{V}_{\mathrm{PQ}}^{\max }$ & $\mathrm{T}^{\min }$ & $\mathbf{T}^{\text {max }}$ \\
\hline 0.9 & 1.1 & 0.94 & 1.06 & 0.9 & 1.1 \\
Limits of the reactive power sources (p.u.) & & \\
Bus No. & $\mathbf{1 8}$ & $\mathbf{2 5}$ & $\mathbf{5 3}$ & & \\
$\mathrm{Q}_{c}^{\min }$ & 0 & 0 & 0 & & \\
$\mathrm{Q}_{c}^{\max }$ & 0.1 & 0.059 & 0.063 & & \\
\hline
\end{tabular}

position at the $i^{\text {th }}$ bus and $T_{i}^{\min }$ and $T_{i}^{\max }$ are its minimum and maximum limits. Equation 8 represents the limits of the reactive power to be injected by the VAR compensators, where $N_{C}$ is the total number of shunt compensators at the buses, $Q_{c i}^{\min }$ and $Q_{c i}^{\max }$ are the minimum and maximum limits of the reactive power injection $Q_{c i}$, respectively. Equations 9 and 10 represent the operating constraints of load buses and the apparent power at the branches, where $N_{P Q}$ depicts the total number of load buses, $S_{L i}^{\max }$ is the maximum apparent power flow at the $i^{\text {th }}$ bus and $S_{L i}$ is the apparent power at that branch. $V_{L i}$ is the magnitude of the voltage at the $i^{\text {th }}$ load bus and $V_{L i}^{\min }$ and $V_{L i}^{\max }$ are its minimum and maximum limits. The objective function in (1) is modified by considering the dependent variables as constraints using penalty coefficients as:

$f=P_{\text {loss }}+\lambda_{V} \sum_{i=1}^{N_{V}^{l i m}}\left(V_{i}-V_{i}^{l i m}\right)^{2}+\lambda_{Q} \sum_{i=1}^{N_{Q}^{l i m}}\left(Q_{g i}-Q_{g i}^{l i m}\right)^{2}$

The limits of $V_{i}^{l i m}$ and $Q_{g i}^{l i m}$ are:

$$
\begin{gathered}
V_{i}^{\text {lim }}= \begin{cases}V_{i}^{\text {min }}, & \text { if } V_{i}<V_{i}^{\text {min }} \\
V_{i}^{\text {max }}, & \text { if } V_{i}>V_{i}^{\text {max }}\end{cases} \\
Q_{i}^{\text {lim }}= \begin{cases}Q_{i}^{\text {min }}, & \text { if } Q_{g i}<Q_{i}^{\text {min }} \\
Q_{i}^{\text {max }}, & \text { if } Q_{g i}>Q_{i}^{\text {max }}\end{cases}
\end{gathered}
$$

where, $\lambda_{V}$ and $\lambda_{Q}$ are the penalty coefficients, $N_{V}^{\lim }$ is the number of buses for which the voltages are outside limits and $N_{Q}^{l i m}$ is the number of buses for which the reactive power generations are outside limits. 
Table 8 Simulation results on the IEEE 57 bus system using different algorithms without DG

\begin{tabular}{|c|c|c|c|c|c|c|c|c|}
\hline Control Variables (p.u.) & PSO & R-PSO & L-PSO & PSO-CFA & IPSO-SR & FOA & MFOA & JAYA \\
\hline$V_{G 1}$ & 1.1 & 1.1 & 1.1 & 1.1 & 1.1 & 0.9127 & 0.9 & 1.1 \\
\hline$V_{G 2}$ & 1.1 & 1.1 & 1.1 & 1.1 & 1.1 & 0.9 & 0.9 & 1.0991 \\
\hline$V_{G 3}$ & 1.1 & 1.1 & 1.1 & 1.1 & 1.1 & 0.9 & 0.9 & 1.0888 \\
\hline$V_{G 6}$ & 1.1 & 1.1 & 1.1 & 1.1 & 1.1 & 0.9 & 0.9 & 1.0834 \\
\hline$V_{G 8}$ & 1.1 & 1.1 & 1.1 & 1.1 & 1.1 & 0.9 & 0.9 & 1.1 \\
\hline$V_{G 9}$ & 1.1 & 1.1 & 1.1 & 1.1 & 1.1 & 0.9 & 0.9 & 1.0848 \\
\hline$V_{G 12}$ & 1.1 & 1.1 & 1.1 & 1.1 & 1.1 & 0.9 & 0.9 & 1.0806 \\
\hline $\mathrm{T}_{4-18}$ & 1.1 & 1.1 & 1.1 & 1.1 & 1.1 & 0.9 & 0.9 & 0.9 \\
\hline $\mathrm{T}_{4-18}$ & 1.1 & 1.1 & 1.1 & 1.1 & 1.1 & 0.9 & 0.9 & 0.9 \\
\hline $\mathrm{T}_{21-20}$ & 1.1 & 1.1 & 1.1 & 0.9918 & 1.1 & 0.9 & 0.9243 & 0.9824 \\
\hline $\mathrm{T}_{24-26}$ & 1.0036 & 1.1 & 1.015 & 0.9971 & 1.0642 & 0.9 & 0.9 & 0.9865 \\
\hline $\mathrm{T}_{7-29}$ & 1.1 & 1.1 & 1.1 & 1.1 & 1.1 & 0.9 & 0.9 & 0.9 \\
\hline$T_{34-32}$ & 0.9671 & 1.1 & 0.9688 & 0.9662 & 1.1 & 1.1 & 0.9 & 0.9751 \\
\hline $\mathrm{T}_{11-41}$ & 1.1 & 1.1 & 1.1 & 1.1 & 1.1 & 0.9 & 0.9 & 0.9 \\
\hline $\mathrm{T}_{15-45}$ & 1.1 & 1.0046 & 1.1 & 1.1 & 1.0133 & 0.9 & 0.9 & 0.9 \\
\hline $\mathrm{T}_{14-46}$ & 1.1 & 1.0095 & 1.1 & 1.1 & 1.0176 & 0.9 & 0.9 & 0.9 \\
\hline $\mathrm{T}_{10-51}$ & 1.1 & 1.1 & 1.1 & 1.1 & 1.1 & 0.9 & 0.9 & 0.9101 \\
\hline $\mathrm{T}_{13-49}$ & 1.1 & 0.9823 & 1.0333 & 1.1 & 0.9895 & 0.9 & 0.9 & 0.9 \\
\hline $\mathrm{T}_{11-43}$ & 1.1 & 1.1 & 1.1 & 1.1 & 1.1 & 0.9 & 0.9 & 0.9 \\
\hline $\mathrm{T}_{40-56}$ & 1.1 & 1.1 & 1.1 & 1.027 & 1.1 & 0.9 & 0.9 & 1.0111 \\
\hline $\mathrm{T}_{39-57}$ & 1.1 & 1.1 & 1.1 & 0.9829 & 1.1 & 0.9 & 0.9 & 0.9841 \\
\hline$T_{9-55}$ & 1.1 & 1.1 & 1.1 & 1.1 & 1.1 & 0.9 & 0.9 & 0.9002 \\
\hline$Q_{5 c 18}$ & 0.0 & 0.0 & 0.0 & 0.10 & 0.0616 & 0.0012 & 0.008 & 0.0976 \\
\hline $\mathrm{Q}_{5 \mathrm{c} 25}$ & 0.059 & 0.059 & 0.059 & 0.059 & 0.059 & 0.0026 & 0.0059 & 0.059 \\
\hline $\mathrm{Q}_{5 c 53}$ & 0.063 & 0.063 & 0.063 & 0.063 & 0.063 & 0.0014 & 0.0059 & 0.063 \\
\hline$P_{\text {loss }}(\mathrm{MW})$ & 24.8254 & 24.2539 & 24.5676 & 24.5873 & 24.2012 & 33.5557 & 23.0158 & 21.5481 \\
\hline ALC-PSO [18] & $\mathrm{BBO}[18]$ & GSA [18] & CPVEI HBMO [18] & HBMO [18] & OGSA [18] & BSO 1 [18] & BSO 2 [18] & BSO 3 [18] \\
\hline 23.39 & 24.544 & 24.439 & 22.78 & 23.24 & 23.43 & 24.5025 & 24.4856 & 24.4492 \\
\hline BSO 4 [18] & BSO 5 [18] & $\mathrm{SGA}\left(F_{f 1}\right)[36]$ & $\operatorname{SGA}\left(F_{f 2}\right)[36]$ & PSO [37] & ICA [37] & PSO-ICA [37] & MOALO [38] & DSA [39] \\
\hline 24.3744 & 24.6431 & 23.836 & 24.325 & 24.7742 & 24.1607 & 24.1386 & 26.593 & 23.35 \\
\hline $\mathrm{BSO}[40]$ & WCA [41] & GBWCA [41] & GSA [42] & CSA [42] & MCBOA [42] & $\mathrm{BA}[43]$ & FPA [43] & \\
\hline 24.3744 & 24.82 & 23.27 & 24.4922 & 24.2619 & 23.6943 & 24.9254 & 24.8419 & \\
\hline
\end{tabular}

\section{JAYA algorithm}

Many stochastic and meta-heuristic techniques have been developed recently to solve this type of complex and non-linear problem such as is the ORPD, including the JAYA algorithm proposed by R.V. Rao [23]. This algorithm has the ability to solve the optimization problem quickly to determine the optimal solution. It has a very high success and convergence rate compared with other algorithms as it has a tendency to move towards the best solution and move away from the worst in every iteration. This helps the algorithm to update new solutions by comparing it with the best without being stuck in local optima.

Let an objective function be $f(x)$, where ' $m$ ' is the number of design variables (i.e. $a=1,2, \ldots, m$ ) and ' $n$ ' the number of populations $(b=1,2, \ldots, n)$ for the $i^{t h}$ iteration. The population having the best solution of $f(x)$ (i.e. $f(x)_{\text {best }}$ ) is called the best candidate and the population having the worst solution to the objective function (i.e. $f(x)_{\text {worst }}$ ) is called the worst. Assuming the value for the $a^{\text {th }}$ variable of the $b^{\text {th }}$ 


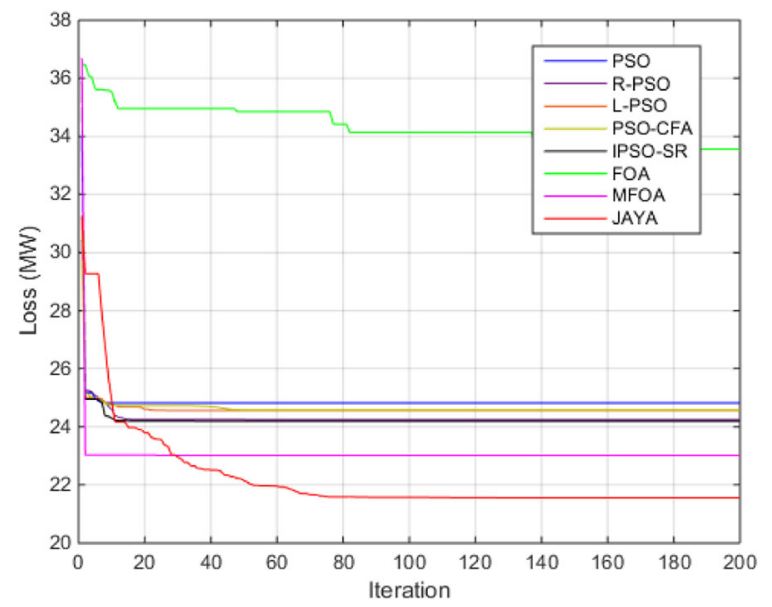

Fig. 4 Convergence characteristics of the algorithms for the IEEE 57 bus system without DG injection

population in the $i^{\text {th }}$ iteration is represented as $J_{a, b}$, $i$, the value of the variable is updated as:

$$
J^{\prime}{ }_{a, b, i}=J_{a, b, i}+r_{1}\left(J_{a, b e s t, i}-\left|J_{a, b, i}\right|\right)-r_{2}\left(J_{a, \text { worst }, i}-\left|J_{a, b, i}\right|\right)
$$

where $J_{a, b e s t, i}$ and $J_{a, \text { worst, } i}$ are the best and worst solutions of the objective function of the $a^{\text {th }}$ variable, respectively. $r_{1}$ and $r_{2}$ are two random numbers in the range of $[0,1]$. Thus, this equation helps the variable to move closer to the best solution and away from the worst solution.

\subsection{Implementation of JAYA algorithm in ORPD}

The procedure for the implementation of the JAYA algorithm in solving the ORPD problem is shown in the flow chart in Fig. 1, and the detailed step by step descriptions are given below.

Table 9 Control variable limits (p.u.) for the test cases

\begin{tabular}{|c|c|c|c|c|c|c|c|}
\hline \multicolumn{8}{|c|}{ Limits of voltages and tap-settings (p.u.) } \\
\hline $\mathrm{V}_{\mathrm{g}}^{\min }$ & $\mathrm{V}_{\mathrm{g}}^{\max }$ & $V_{P Q}^{\min }$ & $\mathrm{V}_{\mathrm{PQ}}^{\max }$ & $T^{\min }$ & $\mathrm{T}^{\mathrm{max}}$ & & \\
\hline 0.9 & 1.1 & 0.94 & 1.06 & 0.9 & 1.1 & & \\
\hline \multicolumn{8}{|c|}{ Limits of the reactive power sources (p.u.) } \\
\hline Bus No. & 5 & 34 & 37 & 44 & 45 & 46 & 48 \\
\hline$Q_{c}^{\min }$ & -0.4 & 0 & -0.25 & 0 & 0 & 0 & 0 \\
\hline $\mathrm{Q}_{c}^{\max }$ & 0 & 0.14 & 0 & 0.1 & 0.1 & 0.1 & 0.15 \\
\hline Bus No. & 74 & 79 & 82 & 83 & 105 & 107 & 110 \\
\hline$Q_{c}^{\min }$ & 0 & 0 & 0 & 0 & 0 & 0 & 0 \\
\hline $\mathrm{Q}_{c}^{\max }$ & 0.12 & 0.2 & 0.2 & 0.1 & 0.2 & 0.06 & 0.06 \\
\hline
\end{tabular}

Step 1: The size of the population of the control variables and the total number of iterations for the problem are initialized.

Step 2: The values of the control variables are randomly selected within their corresponding constraint limits.

Step 3: A standard IEEE bus system is chosen and the bus data and line data of the system are updated using the new values from the respective control variables. Then, the load flow operation using the Newton-Raphson method is executed.

Step 4: The constraints are checked and if any constraint is violated, the control variables are re-initialized and steps 2 and 3 are repeated. If no constraint is violated, the power loss is then calculated using the results from the load flow.

Step 5: The best and worst solutions are identified from the set of populations, i.e. the set resulting in the least power loss is declared as the 'best solution' and the set with the highest power loss is declared as the 'worst solution'.

Step 6: The iteration cycle commences.

Step 7: The JAYA algorithm is initiated where the control variables forming the different populations are updated depending on the best and worst solutions using (14).

Step 8: AC load flow is re-executed and the power loss is calculated for all different sets of population.

Step 9: The results are compared to accept and reject the different sets of the control variables in each population depending on the best solution. The set of control variables having the best solution is accepted and ones with the worse solutions are updated with the previous best. Thus, a new best solution is determined after each iteration.

Step 10: The process continues until the iteration reaches the maximum iteration.

Step 11: The optimal solution is obtained and the corresponding control variables are saved.

This whole process helps obtain the optimal values of the control variables for the best solution among all the sets of population.

\section{Simulation results and discussions}

To evaluate the performance of the JAYA algorithm, it is initially tested on 24 standard constrained benchmark functions (G01 - G24) and the results are compared in Table 1. It shows that the proposed algorithm 
Table 10 Simulation results on the IEEE 118 bus system using different algorithms without DG injection

\begin{tabular}{|c|c|c|c|c|c|c|c|c|}
\hline $\begin{array}{l}\text { Control Variables } \\
\text { (p.u.) }\end{array}$ & PSO & R-PSO & L-PSO & PSO-CFA & IPSO-SR & FOA & MFOA & JAYA \\
\hline$V_{G 1}$ & 1.1 & 1.1 & 1.1 & 1.1 & 1.1 & 0.9 & 0.9 & 1.0801 \\
\hline$V_{G 4}$ & 1.1 & 1.1 & 1.1 & 1.1 & 1.1 & 0.9 & 0.9 & 1.1 \\
\hline$V_{G 6}$ & 1.1 & 1.1 & 1.1 & 1.1 & 1.1 & 0.9 & 0.9 & 1.0932 \\
\hline$V_{G 8}$ & 1.1 & 1.1 & 1.1 & 1.1 & 1.1 & 0.9 & 0.9 & 1.1 \\
\hline$V_{G 10}$ & 1.1 & 1.1 & 1.1 & 1.1 & 1.1 & 0.9 & 0.9 & 1.1 \\
\hline$V_{G 12}$ & 1.1 & 1.1 & 1.1 & 1.1 & 1.1 & 0.9 & 0.9 & 1.0896 \\
\hline$V_{G 15}$ & 1.1 & 1.1 & 1.1 & 1.1 & 1.1 & 0.9 & 0.9 & 1.0882 \\
\hline$V_{G 18}$ & 1.1 & 1.1 & 1.1 & 1.1 & 1.1 & 0.9 & 0.9 & 1.0886 \\
\hline$V_{G 19}$ & 1.1 & 1.1 & 1.1 & 1.1 & 1.1 & 0.9 & 0.9 & 1.0869 \\
\hline$V_{G 24}$ & 1.1 & 1.1 & 1.1 & 1.1 & 1.1 & 0.9 & 0.9 & 1.0912 \\
\hline$V_{G 25}$ & 1.1 & 1.1 & 1.1 & 1.1 & 1.1 & 0.9 & 0.9 & 1.1 \\
\hline$V_{G 26}$ & 1.1 & 1.1 & 1.1 & 1.1 & 1.1 & 0.9 & 0.9 & 1.1 \\
\hline$V_{G 27}$ & 1.1 & 1.1 & 1.1 & 1.1 & 1.1 & 0.9 & 0.9 & 1.0812 \\
\hline$V_{G 31}$ & 1.1 & 1.1 & 1.1 & 1.1 & 1.1 & 0.9 & 0.9 & 1.0755 \\
\hline$V_{G 32}$ & 1.1 & 1.1 & 1.1 & 1.1 & 1.1 & 0.9 & 0.9 & 1.0813 \\
\hline$V_{G 34}$ & 1.1 & 1.1 & 1.1 & 1.1 & 1.1 & 0.9 & 0.9 & 1.0989 \\
\hline$V_{G 36}$ & 1.1 & 1.1 & 1.1 & 1.1 & 1.1 & 0.9 & 0.9 & 1.096 \\
\hline$V_{G 40}$ & 1.1 & 1.1 & 1.1 & 1.1 & 1.1 & 0.9 & 0.9 & 1.0784 \\
\hline$V_{G 42}$ & 1.1 & 1.1 & 1.1 & 1.1 & 1.1 & 0.9437 & 0.9 & 1.078 \\
\hline$V_{G 46}$ & 1.1 & 1.1 & 1.1 & 1.1 & 1.1 & 0.9 & 0.9 & 1.0855 \\
\hline$V_{G 49}$ & 1.1 & 1.1 & 1.1 & 1.1 & 1.1 & 0.9 & 0.9 & 1.0977 \\
\hline$V_{G 54}$ & 1.1 & 1.1 & 1.1 & 1.1 & 1.1 & 0.9 & 0.9 & 1.0771 \\
\hline$V_{G 55}$ & 1.1 & 1.1 & 1.1 & 1.1 & 1.1 & 0.9 & 0.9 & 1.0756 \\
\hline$V_{G 56}$ & 1.1 & 1.1 & 1.1 & 1.1 & 1.1 & 0.9 & 0.9 & 1.0765 \\
\hline$V_{G 59}$ & 1.1 & 1.1 & 1.1 & 1.1 & 1.1 & 0.9 & 0.9 & 1.0994 \\
\hline$V_{G 61}$ & 1.1 & 1.1 & 1.1 & 1.1 & 1.1 & 0.9 & 0.9 & 1.0994 \\
\hline$V_{G 62}$ & 1.1 & 1.1 & 1.1 & 1.1 & 1.1 & 0.9 & 0.9 & 1.0956 \\
\hline$V_{G 65}$ & 1.1 & 1.1 & 1.1 & 1.1 & 1.1 & 0.9 & 0.9 & 1.1 \\
\hline$V_{G 66}$ & 1.1 & 1.1 & 1.1 & 1.1 & 1.1 & 0.9 & 0.9 & 1.1 \\
\hline$V_{G 69}$ & 1.1 & 1.1 & 1.1 & 1.1 & 1.1 & 0.956 & 0.9 & 1.0999 \\
\hline$V_{G 70}$ & 1.1 & 1.1 & 1.1 & 1.1 & 1.1 & 0.9 & 0.9 & 1.0776 \\
\hline$V_{G 72}$ & 1.1 & 1.1 & 1.1 & 1.1 & 1.1 & 0.9 & 0.9 & 1.081 \\
\hline$V_{G 73}$ & 1.1 & 1.1 & 1.1 & 1.1 & 1.1 & 0.9 & 0.9 & 1.0769 \\
\hline$V_{G 74}$ & 1.1 & 1.1 & 1.1 & 1.1 & 1.1 & 0.9 & 0.9 & 1.0669 \\
\hline$V_{G 76}$ & 1.1 & 1.1 & 1.1 & 1.1 & 1.1 & 0.9 & 0.9 & 1.0673 \\
\hline$V_{G 77}$ & 1.1 & 1.1 & 1.1 & 1.1 & 1.1 & 0.9 & 0.9 & 1.0867 \\
\hline$V_{G 80}$ & 1.1 & 1.1 & 1.1 & 1.1 & 1.1 & 0.9 & 0.9 & 1.0994 \\
\hline$V_{G 85}$ & 1.1 & 1.1 & 1.1 & 1.1 & 1.1 & 0.9 & 0.9 & 1.0995 \\
\hline$V_{G 87}$ & 1.1 & 1.1 & 1.1 & 1.1 & 1.1 & 0.9 & 0.9 & 1.1 \\
\hline$V_{G 89}$ & 1.1 & 1.1 & 1.1 & 1.1 & 1.1 & 0.9 & 0.9 & 1.1 \\
\hline$V_{G 90}$ & 1.1 & 1.1 & 1.1 & 1.1 & 1.1 & 0.9 & 0.9 & 1.0854 \\
\hline$V_{G 91}$ & 1.1 & 1.1 & 1.1 & 1.1 & 1.1 & 0.9 & 0.9 & 1.0895 \\
\hline$V_{G 92}$ & 1.1 & 1.1 & 1.1 & 1.1 & 1.1 & 0.9 & 0.9 & 1.1 \\
\hline$V_{G 99}$ & 1.1 & 1.1 & 1.1 & 1.1 & 1.1 & 0.9 & 0.9 & 1.0969 \\
\hline
\end{tabular}


Table 10 Simulation results on the IEEE 118 bus system using different algorithms without DG injection (Continued)

\begin{tabular}{|c|c|c|c|c|c|c|c|c|}
\hline $\begin{array}{l}\text { Control Variables } \\
\text { (p.u.) }\end{array}$ & PSO & R-PSO & L-PSO & PSO-CFA & IPSO-SR & FOA & MFOA & JAYA \\
\hline$\overline{V_{G 100}}$ & 1.1 & 1.1 & 1.1 & 1.1 & 1.1 & 0.9 & 0.9 & 1.1 \\
\hline$V_{G 103}$ & 1.1 & 1.1 & 1.1 & 1.1 & 1.1 & 0.9 & 0.9 & 1.0918 \\
\hline$V_{G 104}$ & 1.1 & 1.1 & 1.1 & 1.1 & 1.1 & 0.9 & 0.9 & 1.083 \\
\hline$V_{G 105}$ & 1.1 & 1.1 & 1.1 & 1.1 & 1.1 & 0.9 & 0.9 & 1.077 \\
\hline$V_{G 107}$ & 1.1 & 1.1 & 1.1 & 1.1 & 1.1 & 0.9 & 0.9 & 1.0669 \\
\hline$V_{G 110}$ & 1.1 & 1.1 & 1.1 & 1.1 & 1.1 & 0.9 & 0.9 & 1.0704 \\
\hline$V_{G 111}$ & 1.1 & 1.1 & 1.1 & 1.1 & 1.1 & 0.9 & 0.9 & 1.0774 \\
\hline$V_{G 112}$ & 1.1 & 1.1 & 1.1 & 1.1 & 1.1 & 0.9 & 0.9 & 1.0549 \\
\hline$V_{G 113}$ & 1.1 & 1.1 & 1.1 & 1.1 & 1.1 & 0.9 & 0.9 & 1.0968 \\
\hline$V_{G 116}$ & 1.1 & 1.1 & 1.1 & 1.1 & 1.1 & 0.9 & 0.9 & 1.0999 \\
\hline$T_{5-8}$ & 0.9905 & 1.1 & 1.1 & 1.1 & 1.1 & 0.9 & 0.9 & 0.9847 \\
\hline $\mathrm{T}_{25-26}$ & 1.1 & 1.1 & 1.1 & 1.1 & 1.1 & 0.922 & 0.9 & 1.0967 \\
\hline $\mathrm{T}_{17-30}$ & 1.1 & 1.1 & 1.1 & 1.1 & 1.1 & 0.9 & 0.9 & 0.9964 \\
\hline$T_{37-38}$ & 1.1 & 1.1 & 1.1 & 1.1 & 0.9942 & 0.9 & 0.9 & 0.983 \\
\hline$T_{59-63}$ & 1.1 & 0.982 & 0.9820 & 0.9821 & 0.9667 & 0.9 & 0.9 & 0.9806 \\
\hline$T_{61-64}$ & 0.9859 & 0.9999 & 0.9999 & 1.0 & 1.1 & 0.9 & 0.9 & 1.005 \\
\hline $\mathrm{T}_{65-66}$ & 1.1 & 1.1 & 1.1 & 1.1 & 1.1 & 0.9 & 0.9 & 1.0043 \\
\hline $\mathrm{T}_{68-69}$ & 1.1 & 1.1 & 1.1 & 1.1 & 0.9257 & 0.9 & 0.9 & 0.9569 \\
\hline $\mathrm{T}_{80-81}$ & 0.9789 & 1.1 & 1.1 & 0.9766 & 1.1 & 0.9 & 0.9 & 0.9915 \\
\hline $\mathrm{Q}_{\mathrm{sc5}}$ & 0.0 & 0.0 & 0.0 & 0.0 & 0.0 & 0.0000 & 0.0 & -0.2340 \\
\hline $\mathrm{Q}_{\text {sc34 }}$ & 0.0 & 0.0 & 0.0 & 0.0 & 0.0 & 0.0017 & 0.14 & 0.0007 \\
\hline $\mathrm{Q}_{\text {sC37 }}$ & 0.0 & 0.0 & 0.0 & 0.0 & 0.0 & 0.0000 & 0.0 & 0.0 \\
\hline $\mathrm{Q}_{544}$ & 0.0 & 0.0 & 0.0 & 0.0 & 0.0 & 0.0007 & 0.1 & 0.0566 \\
\hline $\mathrm{Q}_{\mathrm{sc45}}$ & 0.0 & 0.0 & 0.0 & 0.0 & 0.0 & 0.0009 & 0.1 & 0.0979 \\
\hline $\mathrm{Q}_{\mathrm{sc46}}$ & 0.0 & 0.0 & 0.0 & 0.0 & 0.0 & 0.0019 & 0.1 & 0.0467 \\
\hline $\mathrm{Q}_{\mathrm{sc48}}$ & 0.0 & 0.0 & 0.0 & 0.0 & 0.0 & 0.0007 & 0.15 & 0.0015 \\
\hline $\mathrm{Q}_{\mathrm{sc74}}$ & 0.0 & 0.0 & 0.0 & 0.0 & 0.0 & 0.0008 & 0.12 & 0.0080 \\
\hline $\mathrm{Q}_{\text {sc79 }}$ & 0.0 & 0.0 & 0.0 & 0.0 & 0.0 & 0.0009 & 0.1604 & 0.1992 \\
\hline $\mathrm{Q}_{\text {sc82 }}$ & 0.0 & 0.0 & 0.0 & 0.0 & 0.0 & 0.0005 & 0.1604 & 0.2000 \\
\hline $\mathrm{Q}_{\text {sc83 }}$ & 0.0 & 0.0 & 0.0 & 0.0 & 0.0 & 0.0013 & 0.1 & 0.0741 \\
\hline$Q_{s c 105}$ & 0.0 & 0.0 & 0.0 & 0.0 & 0.0 & 0.0008 & 0.1604 & 0.1991 \\
\hline$Q_{\text {sc107 }}$ & 0.0 & 0.0 & 0.0 & 0.0 & 0.0 & 0.0013 & 0.06 & 0.0 \\
\hline$Q_{\text {sc110 }}$ & 0.0 & 0.06 & 0.06 & 0.0 & 0.06 & 0.0028 & 0.06 & 0.0294 \\
\hline$P_{\text {loss }}(\mathrm{MW})$ & 111.7172 & 113.7233 & 113.7233 & 112.8162 & 112.6259 & 167.0409 & 107.9321 & 105.4821 \\
\hline CKHA [44] & $\begin{array}{l}\text { PSO-TVIW } \\
{[45]}\end{array}$ & $\begin{array}{l}\text { PSO-TVAC } \\
{[45]}\end{array}$ & $\begin{array}{l}\text { SPSO-TVAC } \\
{[45]}\end{array}$ & PSO-CF [45] & $\begin{array}{l}\text { PG-PSO } \\
{[45]}\end{array}$ & $\begin{array}{l}\text { SWT-PSO } \\
{[45]}\end{array}$ & $\begin{array}{l}\text { PGSWT-PSO } \\
{[45]}\end{array}$ & $\begin{array}{l}\text { IPGS-PSO } \\
{[45]}\end{array}$ \\
\hline 110.79 & 116.8976 & 124.3335 & 116.2026 & 115.6469 & 116.6075 & 124.1476 & 119.4271 & 115.0605 \\
\hline GSA [46] & OGSA [47] & CLPSO [48] & EMA [49] & $\begin{array}{l}\text { NGBWCA } \\
{[41]}\end{array}$ & WCA [41] & SARCGA [20] & HEP [20] & QOTLBO [20] \\
\hline 127.76 & 126.99 & 130.96 & 126.22 & 121.47 & 131.83 & 113.12 & 115.58 & 112.2789 \\
\hline TLBO [20] & FPA [20] & CSA [20] & SSA [20] & MSSA [20] & HSSSA [20] & SSO [20] & ISSO [20] & MSFS [50] \\
\hline 116.4003 & 129.6524 & 121.2732 & 125.8324 & 124.0818 & 126.6992 & 179.1816 & 114.5297 & 114.6251 \\
\hline SARCGA [51] & HEP [51] & ALO [21] & IALO [21] & & & & & \\
\hline 113.12 & 115.58 & 116.86 & 114.795 & & & & & \\
\hline
\end{tabular}




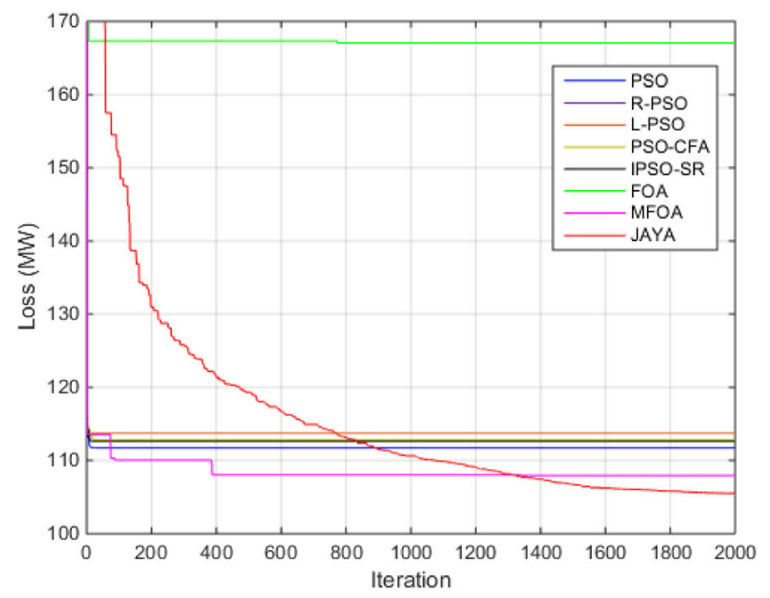

Fig. 5 Convergence characteristics of the algorithms for the IEEE 118 bus system without DG injection

is far superior and consistent in obtaining better results than the other well-established techniques. The results also depict the ability of the proposed technique in obtaining better results for all the functions under any constraints. The best and the mean values for each function using the JAYA algorithm are very close to each other, which implies that the algorithm is robust and produces results with minimum deviation compared to other techniques.

After obtaining this excellent performance of the proposed algorithm on the standard benchmark function with constraints, it is then implemented to solve the ORPD problem. In this paper, it is tested on the standard IEEE 14, 30, 57 and 118 bus systems along with other algorithms from the literature. It has also been tested to solve the minimum power loss of the ORPD problem with and without DG penetration, and the solutions are compared to those using different algorithms. The software used is
MATLAB 2014b and the population size is 100 for all the cases in the paper.

The details of the number of individual parameters of the test systems are listed in Table 2 and the system data of these test systems are obtained from [31].

\subsection{Minimization of active power loss without DG injection}

\subsubsection{IEEE 14 bus system}

The IEEE-14 bus system has five generators at buses 1 (which is the slack bus), 2, 3, 6 and 8, respectively. There are 20 branches, and three tap-changing transformers between the lines 4-7, 4-9 and 5-6. Reactive power is injected at buses 9 and 14. The limits of the control variables (p.u. value) for the case study under the IEEE 14 bus system are as follows:

$0.95 \leq \mathrm{V}_{\mathrm{g}} \leq 1.1 ; 0.95 \leq \mathrm{V}_{\mathrm{PQ}} \leq 1.05 ; 0.9 \leq \mathrm{T}_{\mathrm{i}} \leq 1.1$ and $0 \leq$ $\mathrm{Q}_{\mathrm{c}} \leq 0.3$.

The above control variables are used to solve the ORPD problem using the different algorithms and the simulation results are compared in Table 3 to determine the best among them. Comparing the results in the table and the convergence characteristics shown in Fig. 2, it can be concluded that the JAYA algorithm has produced the best solution to the ORPD problem with a minimum loss of $12.227 \mathrm{MW}$, and is superior to the other 37 algorithms.

\subsubsection{IEEE 30 bus system}

In the IEEE 30 bus system, there exist six generators situated at buses 1, 2, 5, 8, 11 and 13, respectively. Bus no. 1 is the slack bus, and there are 41 transmission lines with four branches having tap-changing transformers. Reactive power is injected by capacitor banks at bus no. 3, 10 and 24 , respectively. The limits of the control variables (p.u. value) are as follows:

$0.95 \leq \mathrm{V}_{\mathrm{g}} \leq 1.1 ; 0.95 \leq \mathrm{V}_{\mathrm{PQ}} \leq 1.1 ; 0.9 \leq \mathrm{T}_{\mathrm{i}} \leq 1.1$ and $0 \leq$ $\mathrm{Q}_{\mathrm{c}} \leq 0.36$.

Table 11 Optimum solution for the IEEE 14 bus system with DG individually injected at each bus using JAYA algorithm

\begin{tabular}{|c|c|c|c|c|c|}
\hline Bus No. & Optimal DG value and Loss & Bus No. & Optimal DG value and Loss & Bus No. & Optimal DG value and Loss \\
\hline 2 & $\begin{array}{l}\mathrm{DG}=178.8543 \mathrm{MW} \\
\text { Loss }=7.7859 \mathrm{MW}\end{array}$ & 7 & $\begin{array}{l}\mathrm{DG}=171.2628 \mathrm{MW} \\
\text { Loss }=3.903 \mathrm{MW}\end{array}$ & 12 & $\begin{array}{l}\mathrm{DG}=45.3501 \mathrm{MW} \\
\text { Loss }=9.9391 \mathrm{MW}\end{array}$ \\
\hline 3 & $\begin{array}{l}\mathrm{DG}=145.6164 \mathrm{MW} \\
\text { Loss }=3.4680 \mathrm{MW}\end{array}$ & 8 & $\begin{array}{l}\mathrm{DG}=167.2458 \mathrm{MW} \\
\text { Loss }=3.9819 \mathrm{MW}\end{array}$ & 13 & $\begin{array}{l}\mathrm{DG}=77.5109 \mathrm{MW} \\
\text { Loss }=8.2191 \mathrm{MW}\end{array}$ \\
\hline 4 & $\begin{array}{l}\mathrm{DG}=190.176833 \mathrm{MW} \\
\text { Loss }=2.9641 \mathrm{MW}\end{array}$ & 9 & $\begin{array}{l}\mathrm{DG}=151.8885 \mathrm{MW} \\
\text { Loss }=3.9819 \mathrm{MW}\end{array}$ & 14 & $\begin{array}{l}\mathrm{DG}=66.8016 \mathrm{MW} \\
\text { Loss }=8.3292 \mathrm{MW}\end{array}$ \\
\hline 5 & $\begin{array}{l}\mathrm{DG}=186.7737 \mathrm{MW} \\
\text { Loss }=4.6521 \mathrm{MW}\end{array}$ & 10 & $\begin{array}{l}\mathrm{DG}=100.6044 \mathrm{MW} \\
\text { Loss }=7.1674 \mathrm{MW}\end{array}$ & & \\
\hline 6 & $\begin{array}{l}\mathrm{DG}=121.6318 \mathrm{MW} \\
\text { Loss }=7.1825 \mathrm{MW}\end{array}$ & 11 & $\begin{array}{l}\mathrm{DG}=72.7414 \mathrm{MW} \\
\text { Loss }=8.8081 \mathrm{MW}\end{array}$ & & \\
\hline
\end{tabular}




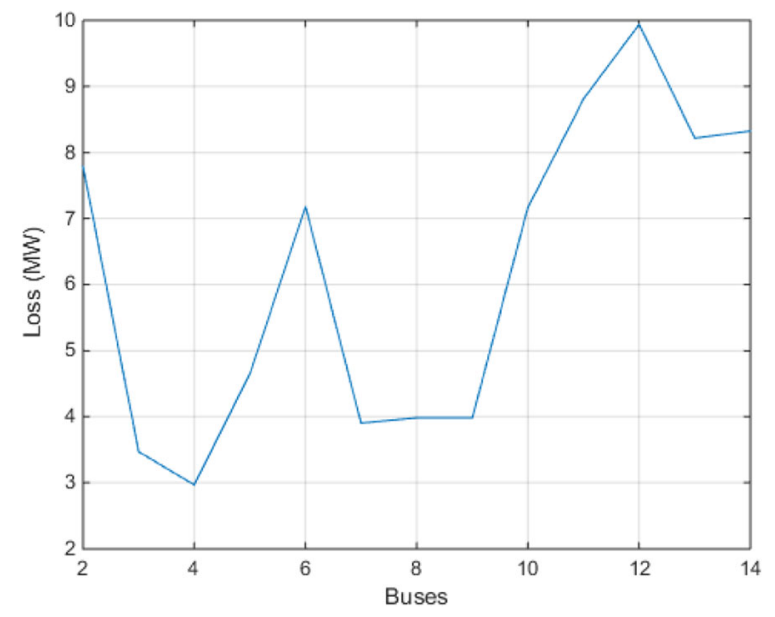

Fig. 6 Comparison of the results for the IEEE 14 bus system using the JAYA algorithm

The simulation results of the solution to the ORPD problem using the different algorithms for this test case are shown in Table 4 along with the convergence characteristics in Fig. 3. It can be seen that the JAYA algorithm has produced the best results under the conditions of the control variables, resulting in the lowest line loss of $4.5983 \mathrm{MW}$.

A statistical analysis of the algorithms is shown in Table 5 for this particular test system. The best and worst values of the solutions of the ORPD problem along with the mean, standard deviation (std.), percentage of power saved, and the average computation time of the results for the different algorithms are compared. The results prove that the JAYA

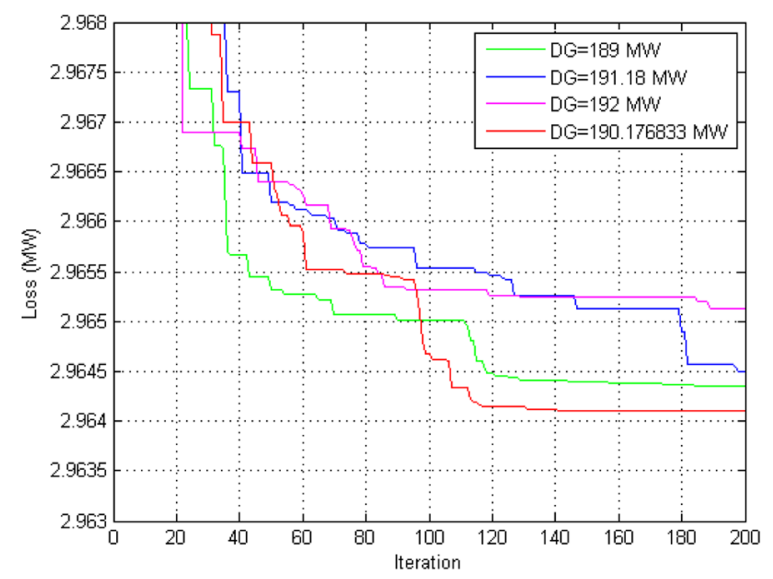

Fig. 7 Convergence characteristics with different DG power placed at bus no. 4 of IEEE 14 bus system using JAYA algorithm algorithm has obtained the best solution to the problem and is also the most consistent and robust with small std. and the maximum reduction of power loss of almost $18.7579 \%$ (4.5983 MW). The time of convergence is modest and although the simulation speed is slower than a few others, the JAYA algorithm obtains the best solution and is much more favorable in terms of efficiency and economy than other methods.

In order to investigate how frequently the results from the different algorithms converge within a different range of solutions, the frequency of convergence for the IEEE 30 bus system under the inequality constraints of the control variables as mentioned earlier is compared in Table 6. It shows the number of times each algorithm has produced the solution within a specified range when the ORPD problem is run for 50 times for every single algorithm. The results show that the JAYA algorithm is undoubtedly the only one to produce all the results within the minimum range of $4.59-4.60 \mathrm{MW}$. Although the MFOA technique is also consistent and has frequently obtained the solutions within the range of 5.11-5.20 MW (49 times), the algorithm has failed to optimize the function to lower limits. Thus, the results prove that the JAYA algorithm has the capability of converging most frequently to the minimum solution.

\subsubsection{IEEE 57 bus system}

The standard IEEE 57 bus system has seven generators situated at buses $1,2,3,6,8,9$ and 12 , respectively, where bus 1 is the slack bus. There are 15 branches out of a total of 80 having tap-changing transformers connected. The reactive power compensating devices are placed at buses 18, 25 and 53. The maximum and minimum limits of the control variables are given in Table 7 .

The simulation results for the ORPD problem using the different algorithms for the test case and the comparative convergence characteristics are shown in Table 8 and Fig. 4, respectively. It shows that the JAYA algorithm has reduced the power loss to $22.67 \%$, a much lower level than the other algorithms. This is the best recorded solution for this particular test case under the mentioned inequality constraints.

\subsubsection{IEEE 118 bus system}

As the algorithm has successfully outperformed the other algorithms reported in the literature in optimizing the ORPD problem for the IEEE 57 bus system, it 
Table 12 Comparison of real power loss at the IEEE 14 bus system with different DG power placed at bus no. 4 using the JAYA algorithm

\begin{tabular}{llcll}
\hline DG values (MW) & 189 & 190.176833 (Optimal) & 191.18 & 192 \\
\hline Loss (MW) & 2.9643 & 2.9641 & 2.9645 & 2.9651 \\
\hline
\end{tabular}

is now tested on the larger IEEE 118 bus system to observe its performance and ability. The IEEE 118 bus system has 54 generators, 14 shunt compensators, 9 tap-changing transformers, and a total of 186 transmission lines. The control variable limits are given in Table 9. Table 10 and Fig. 5 shows the simulation results and the convergence characteristics for the ORPD problem using the different algorithms, respectively.

The results show the superiority of the JAYA algorithm in determining the optimal solution, thus reducing the power loss to the lowest value of 105.4821 MW (20.36\%) for the test case compared to all the other algorithms without violating the limits of the constraints. This proves the JAYA algorithm to be the most efficient algorithms even for large scale power systems.

\subsection{Minimization of power loss with DG injection}

For the second part of the paper, DG power is injected individually at all the buses (except the slack bus) and the power losses are calculated using the same algorithms while keeping the constraints unchanged. The total number of control variables for each case without DG injection was listed in Table 2. When DG is penetrated into the system the number of control variables is increased by 1 , and the

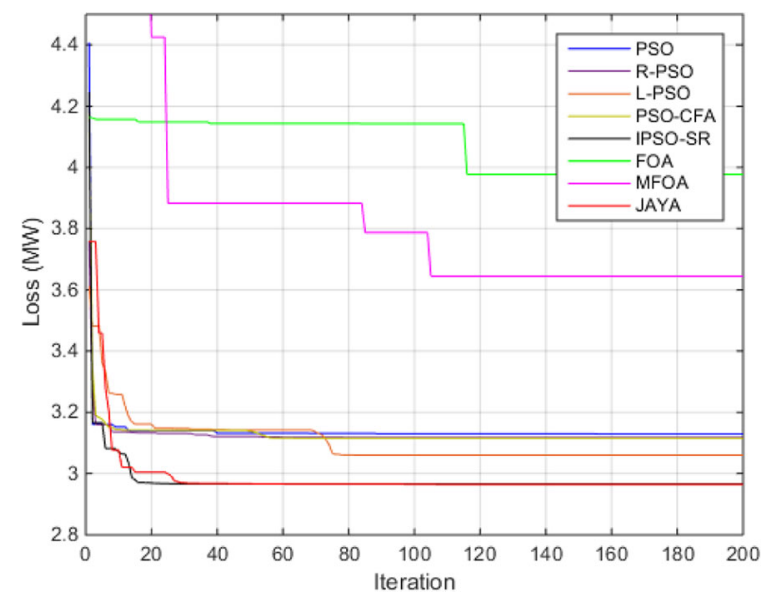

Fig. 8 Convergence characteristics of the algorithms for the IEEE 14 bus system with DG injection
DG power to be injected is taken as an additional control variable. The value of DG power is initially set at $100 \%$ of the maximum load demand for all the test cases considered in this paper. The algorithm then determines the optimal value of DG to be injected at each bus in order to produce the minimum power loss.

Moreover, the magnitude of the voltage of the bus at which the DG is injected is also considered as a control variable. Thus, when the DG is injected at any PV bus, the number of voltage control variables remains the same but for a PQ bus, it increases by 1 .

The JAYA algorithm has been proved to be the best among all the reported algorithms in determining the minimum power loss without incorporating DG power. Thus, the proposed JAYA algorithm is used to determine the optimal value of DG to be injected at each bus to obtain the minimum power loss for all the test systems. The results are then compared and the optimal bus is located with the optimal value of DG to be injected for that particular bus. The study is repeated for all four test cases using different algorithms to determine which algorithm is able to determine the optimal value of DG at that optimal bus leading to minimum power loss. Such work on optimization of the ORPD problem with the concept of DG integration has not been discussed anywhere. This helps significantly reduce the power loss of the system that cannot be achieved using other methods of solving the ORPD problem. Moreover, it also encourages the use of non-conventional resources as the results obtained in this paper describes the details of the optimal amount of DG power to be integrated for a particular test case at the optimal bus location.

\subsubsection{IEEE 14 bus system}

The total generation of the test system is $272.6 \mathrm{MW}$ and the load demand is $259.11 \mathrm{MW}$. The control variable limits are the same as in Section 4.1.1 for the case with no DG. Table 11 shows the optimum solution of the ORPD problem for minimization of power loss when the optimal value of DG is injected at each bus, one at a time using the JAYA algorithm. The comparison of the results is also represented graphically in Fig. 6. From Table 11 and Fig. 6, it is observed that injecting the optimum DG power of $190.176833 \mathrm{MW}$, which is $73.3962 \%$ of the demand, at bus no. 4 can achieve the minimum power loss of $2.9641 \mathrm{MW}$.

Table 12 and Fig. 7 illustrate the significance of the DG power on power loss. The results show that 
Table 13 Simulation results on IEEE 14 bus system with DG using different algorithms

\begin{tabular}{|c|c|c|c|c|c|c|c|c|}
\hline Control Variables (p.u.) & PSO & R-PSO & L-PSO & PSO-CFA & IPSO-SR & FOA & MFOA & JAYA \\
\hline$V_{G 1}$ & 1.1 & 1.1 & 1.1 & 1.1 & 1.1 & 0.95 & 1.1 & 1.1 \\
\hline$V_{G 2}$ & 1.1 & 1.1 & 1.1 & 1.1 & 1.1 & 0.95 & 1.1 & 1.0991 \\
\hline$V_{G 3}$ & 1.1 & 1.1 & 1.1 & 1.1 & 1.0812 & 0.95 & 1.1 & 1.0803 \\
\hline$V_{G 6}$ & 1.1 & 1.0534 & 1.1 & 1.0522 & 1.1 & 1.1 & 1.1 & 1.1 \\
\hline$V_{G 8}$ & 1.1 & 1.0396 & 1.1 & 1.1 & 1.1 & 1.1 & 1.1 & 1.1 \\
\hline $\mathrm{V}_{4}(\mathrm{DG})$ & 1.1 & 1.1 & 1.1 & 1.1 & 1.1 & 0.95 & 1.1 & 0.9564 \\
\hline$T_{4-7}$ & 0.9511 & 1.0286 & 0.9824 & 1.1 & 0.9704 & 0.9 & 1.1 & 1.0847 \\
\hline$T_{4-9}$ & 1.1 & 1.1 & 1.1 & 0.9434 & 1.1 & 0.9 & 1.1 & 0.9 \\
\hline$T_{5-6}$ & 1.1 & 1.1 & 1.0112 & 1.1 & 1.006 & 0.9 & 1.1 & 1.0026 \\
\hline$Q_{5 \subset 9}$ & 0.2309 & 0.3 & 0.3 & 0.0025 & 0.3 & 0.0027 & 0.0 & 0.1882 \\
\hline $\mathrm{Q}_{\mathrm{sc14}}$ & 0.0517 & 0.064 & 0.0604 & 0.0648 & 0.0606 & 0.0004 & 0.0 & 0.0588 \\
\hline $\begin{array}{l}\text { Optimum DG value } \\
\text { at bus no. } 4 \text { (MW) }\end{array}$ & 155.11478 & 192.441259 & 192.226747 & 192.468381 & 192.414496 & 194.465270 & 210.184649 & 190.176833 \\
\hline Total $P_{\text {loss }}(\mathrm{MW})$ & 3.1288 & 3.1179 & 3.0600 & 3.1156 & 2.9660 & 3.9772 & 3.6449 & 2.9641 \\
\hline
\end{tabular}

the power loss would increase from $2.9641 \mathrm{MW}$ to $2.9645 \mathrm{MW}$ and $2.9651 \mathrm{MW}$ for the DG power increased from the optimal value of $190.176833 \mathrm{MW}$ to $191.18 \mathrm{MW}$ and $192 \mathrm{MW}$ respectively, and to $2.9643 \mathrm{MW}$ for the DG power decreased to $189 \mathrm{MW}$. The other reported algorithms are now used to obtain the optimal value of DG at bus no. 4 and the ORPD problem is solved by optimizing the objective function $f$ from (11). Here, the total number of control variables is 12 as the optimal power loss is obtained when the DG is inserted at bus no. 4, which is not a PV bus. The results and the convergence characteristics are shown in Table 13 and Fig. 8, respectively. These prove that the JAYA algorithm produces the best-optimized value compared to all the other algorithms. The results from the two cases

Table 14 Optimum solution for the IEEE 30 bus system with DG individually injected at each bus using the JAYA algorithm

\begin{tabular}{|c|c|c|c|c|c|}
\hline Bus No. & Optimal DG value and Ploss & Bus No. & Optimal DG value and Ploss & Bus No. & Optimal DG value and Ploss \\
\hline 2 & $\begin{array}{l}\mathrm{DG}=65.135046 \mathrm{MW} \\
\text { Ploss }=4.004 \mathrm{MW}\end{array}$ & 12 & $\begin{array}{l}\mathrm{DG}=61.407578 \mathrm{MW} \\
\text { Ploss }=3.3274 \mathrm{MW}\end{array}$ & 22 & $\begin{array}{l}\mathrm{DG}=60.513691 \mathrm{MW} \\
\text { Ploss }=2.7155 \mathrm{MW}\end{array}$ \\
\hline 3 & $\begin{array}{l}\mathrm{DG}=79.182062 \mathrm{MW} \\
\text { Ploss }=3.2109 \mathrm{MW}\end{array}$ & 13 & $\begin{array}{l}\mathrm{DG}=60.745933 \mathrm{MW} \\
\text { Ploss }=3.3402 \mathrm{MW}\end{array}$ & 23 & $\begin{array}{l}\mathrm{DG}=36.462869 \mathrm{MW} \\
\text { Ploss }=3.3324 \mathrm{MW}\end{array}$ \\
\hline 4 & $\begin{array}{l}\mathrm{DG}=98.939426 \mathrm{MW} \\
\text { Ploss }=2.3931 \mathrm{MW}\end{array}$ & 14 & $\begin{array}{l}\mathrm{DG}=26.770762 \mathrm{MW} \\
\text { Ploss }=3.8475 \mathrm{MW}\end{array}$ & 24 & $\begin{array}{l}\mathrm{DG}=44.563769 \mathrm{MW} \\
\text { Ploss }=2.9653 \mathrm{MW}\end{array}$ \\
\hline 5 & $\begin{array}{l}\mathrm{DG}=73.540649 \mathrm{MW} \\
\text { Ploss }=2.4196 \mathrm{MW}\end{array}$ & 15 & $\begin{array}{l}\mathrm{DG}=51.03197 \mathrm{MW} \\
\text { Ploss }=3.0366 \mathrm{MW}\end{array}$ & 25 & $\begin{array}{l}\mathrm{DG}=33.070159 \mathrm{MW} \\
\text { Ploss }=3.4552 \mathrm{MW}\end{array}$ \\
\hline 6 & $\begin{array}{l}\mathrm{DG}=104.34914 \mathrm{MW} \\
\text { Ploss }=1.8574 \mathrm{MW}\end{array}$ & 16 & $\begin{array}{l}\mathrm{DG}=44.027037 \mathrm{MW} \\
\text { Ploss }=3.4411 \mathrm{MW}\end{array}$ & 26 & $\begin{array}{l}\mathrm{DG}=13.511932 \mathrm{MW} \\
\text { Ploss }=4.0246 \mathrm{MW}\end{array}$ \\
\hline 7 & $\begin{array}{l}\mathrm{DG}=81.668016 \mathrm{MW} \\
\text { Ploss }=2.0835 \mathrm{MW}\end{array}$ & 17 & $\begin{array}{l}\mathrm{DG}=62.521769 \mathrm{MW} \\
\text { Ploss }=3.1253 \mathrm{MW}\end{array}$ & 27 & $\begin{array}{l}\mathrm{DG}=46.93759 \mathrm{MW} \\
\text { Ploss }=3.1827 \mathrm{MW}\end{array}$ \\
\hline 8 & $\begin{array}{l}\mathrm{DG}=80.484846 \mathrm{MW} \\
\text { Ploss }=2.3611 \mathrm{MW}\end{array}$ & 18 & $\begin{array}{l}\mathrm{DG}=37.518044 \mathrm{MW} \\
\text { Ploss }=3.2661 \mathrm{MW}\end{array}$ & 28 & $\begin{array}{l}\mathrm{DG}=79.02644 \mathrm{MW} \\
\text { Ploss }=2.3197 \mathrm{MW}\end{array}$ \\
\hline 9 & $\begin{array}{l}\mathrm{DG}=93.083964 \mathrm{MW} \\
\text { Ploss }=2.1163 \mathrm{MW}\end{array}$ & 19 & $\begin{array}{l}\mathrm{DG}=40.023052 \mathrm{MW} \\
\text { Ploss }=3.1379 \mathrm{MW}\end{array}$ & 29 & $\begin{array}{l}\mathrm{DG}=21.634628 \mathrm{MW} \\
\text { Ploss }=3.6982 \mathrm{MW}\end{array}$ \\
\hline 10 & $\begin{array}{l}\mathrm{DG}=79.787423 \mathrm{MW} \\
\text { Ploss }=2.4651 \mathrm{MW}\end{array}$ & 20 & $\begin{array}{l}\mathrm{DG}=41.612227 \mathrm{MW} \\
\text { Ploss }=3.1633 \mathrm{MW}\end{array}$ & 30 & $\begin{array}{l}\mathrm{DG}=22.095693 \mathrm{MW} \\
\text { Ploss }=3.5042 \mathrm{MW}\end{array}$ \\
\hline 11 & $\begin{array}{l}\mathrm{DG}=92.481326 \mathrm{MW} \\
\text { Ploss }=2.1247 \mathrm{MW}\end{array}$ & 21 & $\begin{array}{l}\mathrm{DG}=62.480468 \mathrm{MW} \\
\text { Ploss }=2.6492 \mathrm{MW}\end{array}$ & & \\
\hline
\end{tabular}


Table 15 Comparison of power loss at the IEEE 30 bus system with different DG power placed at bus no. 6 using JAYA algorithm

\begin{tabular}{llll}
\hline DG values (MW) & 103.34914 & 104.34914 (Optimal) & 105.34914 \\
\hline Loss (MW) & 1.8576 & 1.8574 & 1.8587 \\
\hline
\end{tabular}

with and without DG penetration clearly show that the DG penetration has successfully reduced the power loss by $78.03 \%$ compared to a reduction of $9.36 \%$ under the similar condition without DG injection.

\subsubsection{IEEE 30 bus system}

The study on the IEEE 30 bus system has been performed on two different cases. In the first case, the optimal DG power is determined and the value is then fixed to obtain the power loss. However, in the second case, the DG power is considered variable, representing a probabilistic approach to observe the performance penetration of variable DG realistically in the ORPD problem. Here, the probabilistic approach of wind power is considered for the variable DG in the second case.

\subsubsection{Without considering the variability of DG power}

The total active power generation of the test system is 288.7 MW and the load demand is 283.4 MW. The control variable limits are the same as Section 4.1.2 with no DG. Table 14 shows the optimal results of the ORPD problem when DG is individually placed on each bus. As shown, the minimum power loss for the IEEE 30 bus system is obtained when 104.34914 MW DG, which is $36.8204 \%$ of the total demand, is placed at load bus no. 6 . This reduces the power loss to $1.8574 \mathrm{MW}(67.18 \%$ reduction), whereas for the case without DG the loss was reduced by only $18.75 \%$.

The significance of the optimum value of DG obtained by the JAYA algorithm is illustrated in Table 15, which shows that when the DG value is increased or decreased by $1 \mathrm{MW}$ from the optimal value, there is an increase in power loss. Thus, the result obtained from the proposed algorithm is the optimal value of DG to be injected into the system for minimum power loss. Other reported algorithms are then used to optimize the ORPD problem by determining the optimal value of DG at bus no. 6 for minimum power loss. The results from Table 16 and the convergence characteristics from Fig. 9 conclude that the minimum power loss is obtained by using the JAYA algorithm, indicating the superiority of the JAYA algorithm over other reported algorithms.

\subsubsection{Considering the variability of DG power}

In the work shown in Section 4.2.2.1, the uncertainty of DG power was not considered. In practical cases, the DG power is of a variable nature and thus needs to be considered to make the study more realistic. There are several reported cases in which the variability of renewable energy is integrated into the ORPD problem with a maximum capacity of DG of up to $110 \mathrm{MW}$ considered at bus 6. The Weibull probability distribution function [52], which considers the stochastic nature of wind power, is used and the variability of wind power is considered in two ways as follows.

\section{Case 1: Overestimated wind power}

This study shows the impact of overestimated power from the wind farm into the ORPD problem considering the uncertainty condition. The maximum power output from the wind farm is set as $110 \mathrm{MW}$, as the optimal value of injected DG into the IEEE 30 bus system determined by the JAYA algorithm is 104.34914 MW. The overestimated probabilistic approach of the Weibull probability distribution function determines the more realistic nature of the optimal wind power to be injected to minimize the power loss in the ORPD problem using the following equation:

$$
\begin{aligned}
P_{o w i}= & w_{f}\left\{1-\exp \left(-\left(\frac{v_{i}}{c}\right)^{k}\right)+\exp \left(-\left(\frac{v_{o}}{c}\right)^{k}\right)\right\} \\
& +\int_{0}^{W_{1}}\left(w_{f}-w\right) f_{w}(w) d w
\end{aligned}
$$

Table 16 Simulation results on the IEEE 30 bus system with DG injection using different algorithms

\begin{tabular}{lllllllll}
\hline Algorithms & PSO & R-PSO & L-PSO & PSO-CFA & IPSO-SR & FOA & MFOA & JAYA \\
\hline $\begin{array}{l}\text { Optimum DG value at bus no. } 6 \\
\text { (MW) }\end{array}$ & 118.087165 & 104.493446 & 104.604412 & 104.431680 & 101.445626 & 100.164506 & 104.929867 & 104.34914 \\
Ploss $(\mathrm{MW})$ & 2.2330 & 2.0701 & 2.0853 & 2.1283 & 2.0084 & 2.5057 & 2.2652 & 1.8574 \\
\hline
\end{tabular}




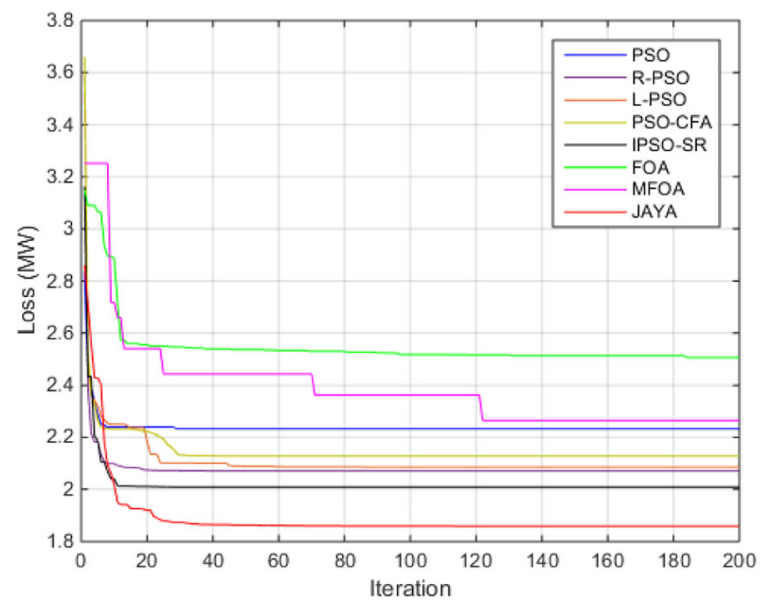

Fig. 9 Convergence characteristics of the algorithms for the IEEE 30 bus system with DG injection

where, $P_{\text {owi }}$ represents the optimal value of injected wind power obtained using the overestimation of the Weibull probability distribution function, and $k$ and $c$ represent the shape and scale factors referred from [52]. $w_{f}$ represents the forecasted wind power and $W_{1}$ represents the actual power produced. The term $f_{w}(w)$ is a probability density function of wind power output $w$, whereas $v_{i}$ and $v_{o}$ are the cut-in and cutout wind velocities, respectively.
The analysis is carried out using the same number of techniques as discussed earlier and the details of the calculated results are shown in Table 17. The convergences of the different algorithms for this case are compared in Fig. 10. The results show that for the overestimation case, the optimal value of wind power is $59.2683 \mathrm{MW}$ (a reduction of $56.82 \%$ compared to the base case) as obtained by the JAYA algorithm, for which the power loss is $2.4442 \mathrm{MW}$. This happens to be the lowest for this case among all the other algorithms. Thus, the analysis gives a realistic outcome of the penetration of wind power for the overestimated condition.

\section{Case 2: Underestimated wind power}

In this case, the underestimated approach of the Weibull probability distribution function is considered. The maximum wind power limit is set as $110 \mathrm{MW}$ and the optimal value of wind power is obtained for minimizing the power loss for the IEEE 30 bus system. The optimal value of the wind power using the Weibull probability distribution function is given as

$$
\begin{aligned}
P_{u w i}= & w_{f}\left\{1-\exp \left(-\left(\frac{v_{r}}{c}\right)^{k}\right)-\exp \left(-\left(\frac{v_{o}}{c}\right)^{k}\right)\right\} \\
& +\int_{w_{1}}^{w_{r}}\left(w-w_{f}\right) f_{w}(w) d w
\end{aligned}
$$

Table 17 Simulation results on the IEEE 30 bus system with overestimated Weibull probability distribution function of wind power

\begin{tabular}{|c|c|c|c|c|c|c|c|c|}
\hline Control Variables (p.u.) & PSO & R-PSO & L-PSO & PSO-CFA & IPSO-SR & FOA & MFOA & JAYA \\
\hline$V_{G 1}$ & 1.1 & 1.1 & 1.1 & 1.1 & 1.1 & 0.95 & 1.1 & 1.1 \\
\hline$V_{G 2}$ & 1.1 & 1.1 & 1.1 & 1.1 & 1.1 & 0.95 & 1.1 & 1.1 \\
\hline$V_{G 5}$ & 1.1 & 1.1 & 1.1 & 1.1 & 1.089 & 0.95 & 1.1 & 1.1 \\
\hline$V_{G 6(D G)}$ & 1.1 & 1.1 & 1.1 & 1.1 & 1.1 & 0.95 & 1.1 & 1.1 \\
\hline$V_{G 8}$ & 1.1 & 1.1 & 1.1 & 1.1 & 1.1 & 1.1 & 1.1 & 1.1 \\
\hline$V_{G 11}$ & 1.1 & 1.1 & 1.0998 & 1.1 & 1.1 & 0.95 & 1.1 & 1.1 \\
\hline$V_{G 13}$ & 1.1 & 1.0879 & 1.0692 & 1.0807 & 1.1 & 1.1 & 1.1 & 0.95 \\
\hline$T_{6-9}$ & 1.1 & 1.1 & 1.1 & 1.1 & 1.1 & 0.9 & 0.9 & 1.1 \\
\hline$T_{6-10}$ & 1.1 & 1.1 & 1.1 & 1.0852 & 1.1 & 0.9 & 0.9 & 0.9 \\
\hline$T_{4-12}$ & 1.1 & 1.0965 & 1.1 & 1.1 & 1.1 & 1.1 & 0.9 & 0.9305 \\
\hline $\mathrm{T}_{28-27}$ & 1.0351 & 1.0243 & 1.0277 & 1.0427 & 1.0219 & 0.9 & 0.9 & 0.9532 \\
\hline $\mathrm{Q}_{\mathrm{sc3}}$ & 0 & 0 & 0.0008 & 0.0008 & 0 & 0.003 & 0.0819 & 0.0897 \\
\hline $\mathrm{Q}_{\text {sc10 }}$ & 0.3241 & 0.2143 & 0.1281 & 0.1945 & 0.2827 & 0.003 & 0.0818 & 0.3104 \\
\hline $\mathrm{Q}_{\mathrm{sc24}}$ & 0.0753 & 0.1109 & 0.0983 & 0.1173 & 0.1038 & 0.003 & 0.0819 & 0.1244 \\
\hline Optimum DG value at bus no. 6 (MW) & 2.3931 & 43.4629 & 48.4923 & 58.5706 & 6.5336 & 53.6444 & 58.7457 & 59.2683 \\
\hline$P_{\text {loss }}(\mathrm{MW})$ & 2.6374 & 2.6006 & 2.605 & 2.6157 & 2.5767 & 3.236 & 2.7915 & 2.4442 \\
\hline
\end{tabular}
on ORPD using different algorithms 
Table 18 Simulation results on the IEEE 30 bus system with underestimated Weibull probability distribution function of wind power on ORPD using different algorithms

\begin{tabular}{|c|c|c|c|c|c|c|c|c|}
\hline Control Variables (p.u.) & PSO & R-PSO & L-PSO & PSO-CFA & IPSO-SR & FOA & MFOA & JAYA \\
\hline$V_{G 1}$ & 1.1 & 1.1 & 1.1 & 1.1 & 1.1 & 0.95 & 1.1 & 1.1 \\
\hline$V_{G 2}$ & 1.1 & 1.1 & 1.1 & 1.1 & 1.1 & 0.95 & 1.1 & 1.1 \\
\hline$V_{G 5}$ & 1.1 & 1.0887 & 1.1 & 1.1 & 1.1 & 0.95 & 1.1 & 1.1 \\
\hline$V_{G 6(D G)}$ & 1.1 & 1.1 & 1.1 & 1.1 & 1.1 & 0.95 & 1.1 & 1.1 \\
\hline$V_{G 8}$ & 1.1 & 1.1 & 1.1 & 1.1 & 1.1 & 0.95 & 1.1 & 1.1 \\
\hline$V_{G 11}$ & 1.1 & 1.1 & 1.1 & 1.1 & 1.0452 & 0.95 & 1.1 & 1.1 \\
\hline$V_{G 13}$ & 1.1 & 1.0722 & 1.1 & 1.1 & 1.1 & 1.1 & 1.1 & 1.1 \\
\hline$T_{6-9}$ & 1.1 & 1.1 & 1.1 & 1.0311 & 1.1 & 0.9 & 0.9 & 1.058 \\
\hline$T_{6-10}$ & 1.1 & 1.1 & 0.999 & 1.1 & 1.1 & 0.9 & 0.9 & 0.9766 \\
\hline$T_{4-12}$ & 1.1 & 1.1 & 1.1 & 1.1 & 1.015 & 1.1 & 0.9 & 0.9521 \\
\hline $\mathrm{T}_{28-27}$ & 1.1 & 1.0321 & 1.1 & 1.1 & 1.004 & 0.9 & 0.9 & 0.9745 \\
\hline $\mathrm{Q}_{\mathrm{sc3}}$ & 0 & 0.0007 & 0 & 0 & 0 & 0.0005 & 0.1313 & 0 \\
\hline$Q_{s c 10}$ & 0.126 & 0.1335 & 0.0907 & 0.1021 & 0.36 & 0.0003 & 0.1313 & 0.36 \\
\hline$Q_{s c 24}$ & 0.1376 & 0.1266 & 0.1429 & 0.1224 & 0.0753 & 0.001 & 0.1313 & 0.0945 \\
\hline Optimum DG value at bus no. 6 (MW) & 9.6579 & 33.4181 & 16.7047 & 11.0877 & 35.7986 & 35.7864 & 50.4481 & 45.856 \\
\hline$P_{\text {loss }}(\mathrm{MW})$ & 3.1203 & 2.9217 & 3.082 & 3.0669 & 2.8972 & 4.0559 & 3.0159 & 2.805 \\
\hline
\end{tabular}

where, $P_{u w i}$ represents the optimal value of injected wind power obtained using the underestimation of the Weibull probability distribution function, The term $v_{i}$ is the rated wind velocity and $w_{r}$ the equivalent rated power of the wind farm.

The analysis is carried out using the different techniques and the results are displayed in Table 18, along with the convergence characteristics shown in

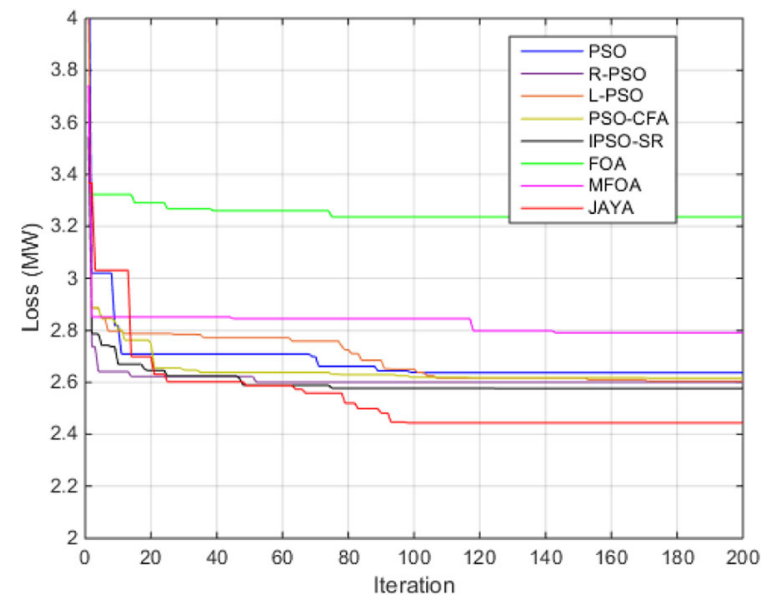

Fig. 10 Convergence characteristics of the algorithms for the IEEE 30 bus system with overestimated Weibull probability distribution function of wind power on ORPD
Fig. 11. The results show that for the underestimated case of uncertain wind power, the optimal power output from the wind farm is $45.856 \mathrm{MW}$ for a power loss of $2.805 \mathrm{MW}$ (50.44\% reduction compared to the base case). This optimal result is obtained using the JAYA algorithm and hence it is proved to be the best in optimizing this Weibull probability distribution function-based ORPD problem. The uncertainty of

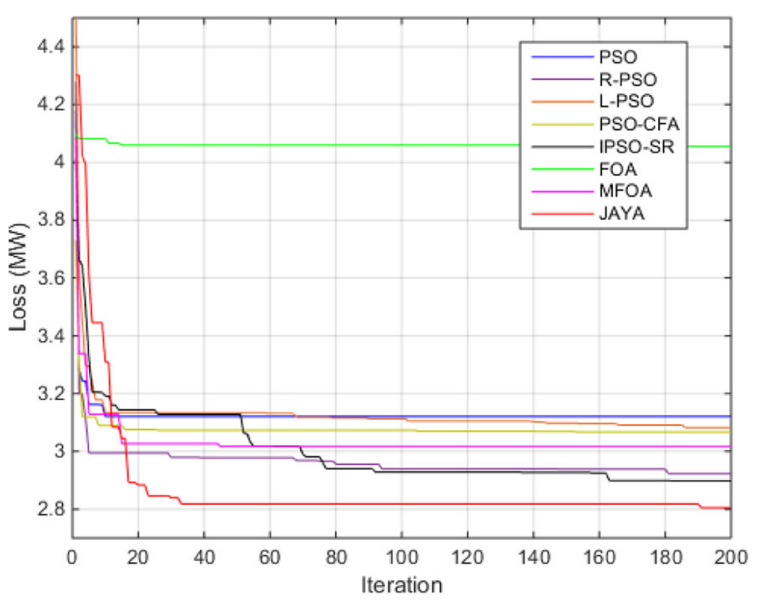

Fig. 11 Convergence characteristics of the algorithms for the IEEE 30 bus system with underestimated Weibull probability distribution function of wind power on ORPD 
Table 19 Optimum solution for the IEEE 57 bus system with DG individually injected at each bus using the JAYA algorithm

\begin{tabular}{|c|c|c|c|c|c|}
\hline Bus No. & Optimal DG value and Ploss & Bus No. & Optimal DG value and Ploss & Bus No. & Optimal DG value and Ploss \\
\hline 2 & $\begin{array}{l}\mathrm{DG}=85.9022 \mathrm{MW} \\
\text { Ploss }=22.9538 \mathrm{MW}\end{array}$ & 21 & $\begin{array}{l}\mathrm{DG}=62.3349 \mathrm{MW} \\
\text { Ploss }=19.8914 \mathrm{MW}\end{array}$ & 40 & $\begin{array}{l}\mathrm{DG}=66.0233 \mathrm{MW} \\
\text { Ploss }=18.7275 \mathrm{MW}\end{array}$ \\
\hline 3 & $\begin{array}{l}\mathrm{DG}=180.4761 \mathrm{MW} \\
\text { Ploss }=18.3962 \mathrm{MW}\end{array}$ & 22 & $\begin{array}{l}\mathrm{DG}=128.6296 \mathrm{MW} \\
\text { Ploss }=16.1145 \mathrm{MW}\end{array}$ & 41 & $\begin{array}{l}\mathrm{DG}=106.9548 \mathrm{MW} \\
\text { Ploss }=18.5122 \mathrm{MW}\end{array}$ \\
\hline 4 & $\begin{array}{l}\mathrm{DG}=154.6043 \mathrm{MW} \\
\text { Ploss }=18.2421 \mathrm{MW}\end{array}$ & 23 & $\begin{array}{l}\mathrm{DG}=114.9209 \mathrm{MW} \\
\text { Ploss }=16.8096 \mathrm{MW}\end{array}$ & 42 & $\begin{array}{l}\mathrm{DG}=50.4274 \mathrm{MW} \\
\text { Ploss }=20.214 \mathrm{MW}\end{array}$ \\
\hline 5 & $\begin{array}{l}\mathrm{DG}=97.4521 \mathrm{MW} \\
\text { Ploss }=19.6006 \mathrm{MW}\end{array}$ & 24 & $\begin{array}{l}\mathrm{DG}=61.6723 \mathrm{MW} \\
\text { Ploss }=19.4454 \mathrm{MW}\end{array}$ & 43 & $\begin{array}{l}\mathrm{DG}=155.9366 \mathrm{MW} \\
\text { Ploss }=16.2739 \mathrm{MW}\end{array}$ \\
\hline 6 & $\begin{array}{l}\mathrm{DG}=128.7671 \mathrm{MW} \\
\text { Ploss }=18.2827 \mathrm{MW}\end{array}$ & 25 & $\begin{array}{l}\mathrm{DG}=49.9298 \mathrm{MW} \\
\text { Ploss }=20.019 \mathrm{MW}\end{array}$ & 44 & $\begin{array}{l}\mathrm{DG}=130.7442 \mathrm{MW} \\
\text { Ploss }=17.0793 \mathrm{MW}\end{array}$ \\
\hline 7 & $\begin{array}{l}\mathrm{DG}=108.5867 \mathrm{MW} \\
\text { Ploss }=19.5623 \mathrm{MW}\end{array}$ & 26 & $\begin{array}{l}\mathrm{DG}=62.1794 \mathrm{MW} \\
\text { Ploss }=19.3917 \mathrm{MW}\end{array}$ & 45 & $\begin{array}{l}\mathrm{DG}=164.6702 \mathrm{MW} \\
\text { Ploss }=18.7277 \mathrm{MW}\end{array}$ \\
\hline 8 & $\begin{array}{l}\mathrm{DG}=95.4473 \mathrm{MW} \\
\text { Ploss }=20.9896 \mathrm{MW}\end{array}$ & 27 & $\begin{array}{l}\mathrm{DG}=59.1934 \mathrm{MW} \\
\text { Ploss }=20.364 \mathrm{MW}\end{array}$ & 46 & $\begin{array}{l}\mathrm{DG}=187.5735 \mathrm{MW} \\
\text { Ploss }=15.7753 \mathrm{MW}\end{array}$ \\
\hline 9 & $\begin{array}{l}\mathrm{DG}=182.4026 \mathrm{MW} \\
\text { Ploss }=15.8598 \mathrm{MW}\end{array}$ & 28 & $\begin{array}{l}\mathrm{DG}=69.4704 \mathrm{MW} \\
\text { Ploss }=20.4721 \mathrm{MW}\end{array}$ & 47 & $\begin{array}{l}\mathrm{DG}=155.3579 \mathrm{MW} \\
\text { Ploss }=15.9026 \mathrm{MW}\end{array}$ \\
\hline 10 & $\begin{array}{l}\mathrm{DG}=156.9776 \mathrm{MW} \\
\text { Ploss }=16.0904 \mathrm{MW}\end{array}$ & 29 & $\begin{array}{l}\mathrm{DG}=91.2441 \mathrm{MW} \\
\text { Ploss }=20.7023 \mathrm{MW}\end{array}$ & 48 & $\begin{array}{l}\mathrm{DG}=162.0502 \mathrm{MW} \\
\text { Ploss }=15.1216 \mathrm{MW}\end{array}$ \\
\hline 11 & $\begin{array}{l}\mathrm{DG}=171.2313 \mathrm{MW} \\
\text { Ploss }=15.7826 \mathrm{MW}\end{array}$ & 30 & $\begin{array}{l}\mathrm{DG}=37.9154 \mathrm{MW} \\
\text { Ploss }=20.5292 \mathrm{MW}\end{array}$ & 49 & $\begin{array}{l}\mathrm{DG}=164.5209 \mathrm{MW} \\
\text { Ploss }=15.22 \mathrm{MW}\end{array}$ \\
\hline 12 & $\begin{array}{l}\mathrm{DG}=253.8512 \mathrm{MW} \\
\text { Ploss }=12.6387 \mathrm{MW}\end{array}$ & 31 & $\begin{array}{l}\mathrm{DG}=30.4513 \mathrm{MW} \\
\text { Ploss }=20.761 \mathrm{MW}\end{array}$ & 50 & $\begin{array}{l}\mathrm{DG}=92.749 \mathrm{MW} \\
\text { Ploss }=18.1263 \mathrm{MW}\end{array}$ \\
\hline 13 & $\begin{array}{l}\mathrm{DG}=271.898815 \mathrm{MW} \\
\text { Ploss }=10.7774 \mathrm{MW}\end{array}$ & 32 & $\begin{array}{l}\mathrm{DG}=38.8860 \mathrm{MW} \\
\text { Ploss }=20.3155 \mathrm{MW}\end{array}$ & 51 & $\begin{array}{l}\mathrm{DG}=131.6244 \mathrm{MW} \\
\text { Ploss }=17.3217 \mathrm{MW}\end{array}$ \\
\hline 14 & $\begin{array}{l}\mathrm{DG}=231.8587 \mathrm{MW} \\
\text { Ploss }=13.9697 \mathrm{MW}\end{array}$ & 33 & $\begin{array}{l}\mathrm{DG}=34.5838 \mathrm{MW} \\
\text { Ploss }=20.6314 \mathrm{MW}\end{array}$ & 52 & $\begin{array}{l}\mathrm{DG}=50.9403 \mathrm{MW} \\
\text { Ploss }=20.5556 \mathrm{MW}\end{array}$ \\
\hline 15 & $\begin{array}{l}\mathrm{DG}=274.1193 \mathrm{MW} \\
\text { Ploss }=15.2984 \mathrm{MW}\end{array}$ & 34 & $\begin{array}{l}\mathrm{DG}=50.41 \mathrm{MW} \\
\text { Ploss }=19.4297 \mathrm{MW}\end{array}$ & 53 & $\begin{array}{l}\mathrm{DG}=49.6756 \mathrm{MW} \\
\text { Ploss }=20.2202 \mathrm{MW}\end{array}$ \\
\hline 16 & $\begin{array}{l}\mathrm{DG}=176.7618 \mathrm{MW} \\
\text { Ploss }=17.1757 \mathrm{MW}\end{array}$ & 35 & $\begin{array}{l}\mathrm{DG}=62.3285 \mathrm{MW} \\
\text { Ploss }=18.7095 \mathrm{MW}\end{array}$ & 54 & $\begin{array}{l}\mathrm{DG}=48.7095 \mathrm{MW} \\
\text { Ploss }=20.7028 \mathrm{MW}\end{array}$ \\
\hline 17 & $\begin{array}{l}\mathrm{DG}=137.62678 \mathrm{MW} \\
\text { Ploss }=20.5061 \mathrm{MW}\end{array}$ & 36 & $\begin{array}{l}\mathrm{DG}=78.0449 \mathrm{MW} \\
\text { Ploss }=17.9115 \mathrm{MW}\end{array}$ & 55 & $\begin{array}{l}\mathrm{DG}=144.5947 \mathrm{MW} \\
\text { Ploss }=17.3363 \mathrm{MW}\end{array}$ \\
\hline 18 & $\begin{array}{l}\mathrm{DG}=119.7668 \mathrm{MW} \\
\text { Ploss }=19.3995 \mathrm{MW}\end{array}$ & 37 & $\begin{array}{l}\mathrm{DG}=90.9933 \mathrm{MW} \\
\text { Ploss }=17.3753 \mathrm{MW}\end{array}$ & 56 & $\begin{array}{l}\mathrm{DG}=65.5031 \mathrm{MW} \\
\text { Ploss }=18.8386 \mathrm{MW}\end{array}$ \\
\hline 19 & $\begin{array}{l}\mathrm{DG}=28.9124 \mathrm{MW} \\
\text { Ploss }=21.9544 \mathrm{MW}\end{array}$ & 38 & $\begin{array}{l}\mathrm{DG}=168.8586 \mathrm{MW} \\
\text { Ploss }=14.1612 \mathrm{MW}\end{array}$ & 57 & $\begin{array}{l}\mathrm{DG}=48.1161 \mathrm{MW} \\
\text { Ploss }=19.9331 \mathrm{MW}\end{array}$ \\
\hline 20 & $\begin{array}{l}\mathrm{DG}=41.2858 \mathrm{MW} \\
\text { Ploss }=21.1097 \mathrm{MW}\end{array}$ & 39 & $\begin{array}{l}\mathrm{DG}=75.1376 \mathrm{MW} \\
\text { Ploss }=18.3595 \mathrm{MW}\end{array}$ & & \\
\hline
\end{tabular}

DG power shows that the actual power under the realistic condition obtained from the wind farm is less than that obtained from Table 14. The overestimated output of wind power is higher than the underestimation and thus gives lower power loss. The difference in power loss is about $0.3608 \mathrm{MW}$ between the two estimations considering the best solutions from the JAYA algorithm.

\subsubsection{EEE 57 bus system}

The IEEE 57 bus system has a total active power generation of 1278.7 MW and a load demand of 1250.8 MW.
The limits of the control variables are the same as Section 4.1.3 with no DG. Table 19 shows the complete results of ORPD for minimizing power loss for 56 different cases where the DG is individually injected at

Table $\mathbf{2 0}$ Comparison of power loss at the IEEE 57 bus system with different DG power placed at bus no. 13 using the JAYA algorithm

\begin{tabular}{lccc}
\hline DG values (MW) & 270.898815 & 271.898815 (Optimal) & 272.898815 \\
\hline Loss $(\mathrm{MW})$ & 10.7857 & 10.7774 & 10.7797 \\
\hline
\end{tabular}


Table 21 Simulation results on IEEE 57 bus system with DG using different algorithms

\begin{tabular}{|c|c|c|c|c|c|c|c|c|}
\hline Algorithms & PSO & R-PSO & L-PSO & PSO-CFA & IPSO-SR & FOA & MFOA & JAYA \\
\hline $\begin{array}{l}\text { Optimum DG value at bus no. } \\
13 \text { (MW) }\end{array}$ & 337.506395 & 275.969626 & 275.829595 & 276.086357 & 286.388354 & 276.823206 & 541.412358 & 271.898815 \\
\hline Total $P_{\text {loss }}(\mathrm{MW})$ & 13.5103 & 13.3015 & 13.5081 & 13.3868 & 13.0453 & 17.6167 & 12.4927 & 10.7774 \\
\hline
\end{tabular}

each bus (except the slack bus no. 1). Table 19 shows that the power loss is minimum (i.e., 10.7774 MW) when 271.898815 MW DG is injected at the.

PQ bus 13 , which is $21.738 \%$ of the total load demand of the system. These results are again obtained by the JAYA algorithm. The results from Table 20 show the significance of the optimal value of DG determined by the JAYA algorithm, as a small variation can lead to increased power loss. Other algorithms have also been used to optimize the ORPD problem by determining the optimum DG value at bus 13 and the results are illustrated in Table 21 and Fig. 12.

From the results, it is concluded that the JAYA algorithm results in significantly lower power loss than the other algorithms.

The study shows that DG penetration reduces the power loss by $61.32 \%$ compared to $22.67 \%$ without DG penetration using the same algorithm.

\subsubsection{IEEE 118 bus system}

The active power generation and load demand of the IEEE 118 bus system are 4374.9 MW and 4242.45 MW, respectively. The limits of the control variables considered for this case are the same as Section 4.2.4 with no DG. Bus 69 is the slack bus,

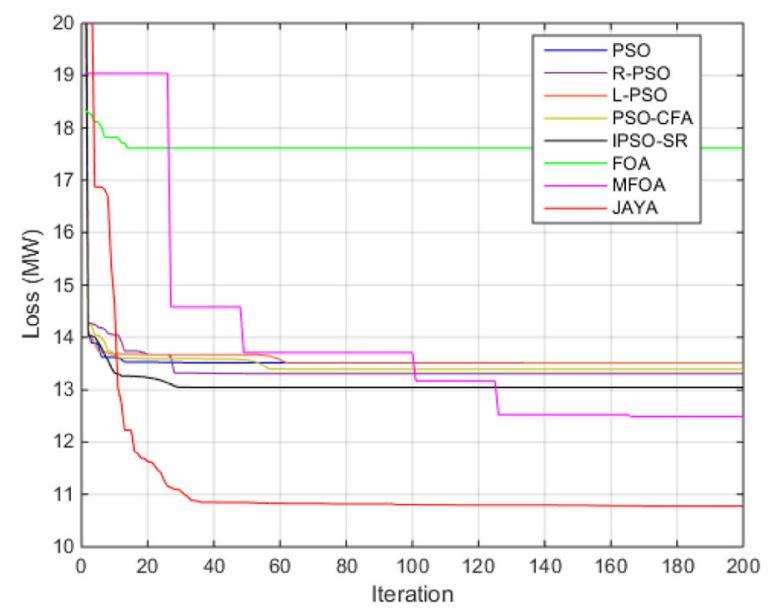

Fig. 12 Convergence characteristics of the algorithms for the IEEE 57 bus system with DG and the ORPD problems are solved using the JAYA algorithm with the individual injection of DG power at each of the other 117 buses. Table 22 shows the details of the 117 solutions and indicates that the minimum power loss of $91.4174 \mathrm{MW}$ is obtained when a DG of power of $235.926829 \mathrm{MW}$ (5.5611\% of the total load demand) is injected at bus 40 . The penetration of DG reduces the power loss by almost $30.98 \%$ with the use of the JAYA algorithm, whereas for the system without DG injection, the proposed algorithm was only able to reduce the power loss by $20.36 \%$.

The significance of the optimal value of DG obtained by the JAYA algorithm is illustrated in Table 23. The data from Table 24 and the convergence characteristics in Fig. 13 compare the results of the ORPD problem using different algorithms. It shows that the results obtained using the JAYA algorithm are the best of all the algorithms. In this case, the JAYA algorithm is not stuck in local optima and is able to optimize the problem to a much larger extent than the others. Thus, the JAYA algorithm is superior to other algorithms reported in the literature for all the test cases shown in this paper with the injection of DG in optimizing the ORPD problem.

\section{Efficacy of JAYA algorithm}

The efficacy of the JAYA algorithm can be explained as follows:

i. Benchmark function - The JAYA algorithm has been tested on 24 standard constrained benchmark functions (G01 - G24) and the results were shown in Table 1 . It has been proved to be the most robust and efficient algorithm by obtaining the best solution to all the different functions. Thus, this benchmark test has proved JAYA to be the best of all the algorithms reported on the optimization problem and thus can be tested on the nonlinear and highly constrained ORPD problem.

ii. ORPD problem without DG - The JAYA algorithm has proved to be the most efficient by consistently providing the optimal solutions to 
Table 22 Optimum solution for the IEEE 118 bus system with DG individually injected at each bus using JAYA algorithm

\begin{tabular}{|c|c|c|c|c|c|}
\hline Bus No. & Optimal DG value and Ploss & Bus No. & Optimal DG value and Ploss & Bus No. & Optimal DG value and Ploss \\
\hline 1 & $\begin{array}{l}\mathrm{DG}=126.691685 \mathrm{MW} \\
\text { Ploss }=102.1306 \mathrm{MW}\end{array}$ & 40 & $\begin{array}{l}\mathrm{DG}=235.926829 \mathrm{MW} \\
\text { Ploss }=91.4174 \mathrm{MW}\end{array}$ & 80 & $\begin{array}{l}\mathrm{DG}=56.72296 \mathrm{MW} \\
\text { Ploss }=111.63 \mathrm{MW}\end{array}$ \\
\hline 2 & $\begin{array}{l}\mathrm{DG}=121.389574 \mathrm{MW} \\
\text { Ploss }=104.5923 \mathrm{MW}\end{array}$ & 41 & $\begin{array}{l}\mathrm{DG}=206.527776 \mathrm{MW} \\
\text { Ploss }=98.5241 \mathrm{MW}\end{array}$ & 81 & $\begin{array}{l}\mathrm{DG}=118.496073 \mathrm{MW} \\
\text { Ploss }=109.2481 \mathrm{MW}\end{array}$ \\
\hline 3 & $\begin{array}{l}\mathrm{DG}=132.474896 \mathrm{MW} \\
\text { Ploss }=106.2292 \mathrm{MW}\end{array}$ & 42 & $\begin{array}{l}\mathrm{DG}=205.316671 \mathrm{MW} \\
\text { Ploss }=99.1168 \mathrm{MW}\end{array}$ & 82 & $\begin{array}{l}\mathrm{DG}=79.090821 \mathrm{MW} \\
\text { Ploss }=106.9809 \mathrm{MW}\end{array}$ \\
\hline 4 & $\begin{array}{l}\mathrm{DG}=115.851608 \mathrm{MW} \\
\text { Ploss }=104.297 \mathrm{MW}\end{array}$ & 43 & $\begin{array}{l}\mathrm{DG}=122.943056 \mathrm{MW} \\
\text { Ploss }=104.8476 \mathrm{MW}\end{array}$ & 83 & $\begin{array}{l}\mathrm{DG}=28.963277 \mathrm{MW} \\
\text { Ploss }=111.2587 \mathrm{MW}\end{array}$ \\
\hline 5 & $\begin{array}{l}\mathrm{DG}=126.830533 \mathrm{MW} \\
\text { Ploss }=102.2818 \mathrm{MW}\end{array}$ & 44 & $\begin{array}{l}\mathrm{DG}=127.95713 \mathrm{MW} \\
\text { Ploss }=105.9838 \mathrm{MW}\end{array}$ & 84 & $\begin{array}{l}\mathrm{DG}=0.285584 \mathrm{MW} \\
\text { Ploss }=109.675 \mathrm{MW}\end{array}$ \\
\hline 6 & $\begin{array}{l}\mathrm{DG}=135.795184 \mathrm{MW} \\
\text { Ploss }=102.7085 \mathrm{MW}\end{array}$ & 45 & $\begin{array}{l}\mathrm{DG}=152.793032 \mathrm{MW} \\
\text { Ploss }=101.936 \mathrm{MW}\end{array}$ & 85 & $\begin{array}{l}\mathrm{DG}=0.262262 \mathrm{MW} \\
\text { Ploss }=106.7078 \mathrm{MW}\end{array}$ \\
\hline 7 & $\begin{array}{l}\mathrm{DG}=141.976923 \mathrm{MW} \\
\text { Ploss }=105.5292 \mathrm{MW}\end{array}$ & 46 & $\begin{array}{l}\mathrm{DG}=129.549348 \mathrm{MW} \\
\text { Ploss }=106.5249 \mathrm{MW}\end{array}$ & 86 & $\begin{array}{l}\mathrm{DG}=0.167232 \mathrm{MW} \\
\text { Ploss }=112.0001 \mathrm{MW}\end{array}$ \\
\hline 8 & $\begin{array}{l}\mathrm{DG}=137.322819 \mathrm{MW} \\
\text { Ploss }=106.3051 \mathrm{MW}\end{array}$ & 47 & $\begin{array}{l}\mathrm{DG}=143.984783 \mathrm{MW} \\
\text { Ploss }=106.5703 \mathrm{MW}\end{array}$ & 87 & $\begin{array}{l}\mathrm{DG}=0.693603 \mathrm{MW} \\
\text { Ploss }=109.3171 \mathrm{MW}\end{array}$ \\
\hline 9 & $\begin{array}{l}\mathrm{DG}=86.098538 \mathrm{MW} \\
\text { Ploss }=108.9833 \mathrm{MW}\end{array}$ & 48 & $\begin{array}{l}\mathrm{DG}=119.983949 \mathrm{MW} \\
\text { Ploss }=108.3803 \mathrm{MW}\end{array}$ & 88 & $\begin{array}{l}\mathrm{DG}=0.403614 \mathrm{MW} \\
\text { Ploss }=109.7036 \mathrm{MW}\end{array}$ \\
\hline 10 & $\begin{array}{l}\mathrm{DG}=31.763133 \mathrm{MW} \\
\text { Ploss }=108.6617 \mathrm{MW}\end{array}$ & 49 & $\begin{array}{l}\mathrm{DG}=238.49512 \mathrm{MW} \\
\text { Ploss }=100.5761 \mathrm{MW}\end{array}$ & 89 & $\begin{array}{l}\mathrm{DG}=0.000003 \mathrm{MW} \\
\text { Ploss }=106.1475 \mathrm{MW}\end{array}$ \\
\hline 11 & $\begin{array}{l}\mathrm{DG}=158.561438 \mathrm{MW} \\
\text { Ploss }=103.3529 \mathrm{MW}\end{array}$ & 50 & $\begin{array}{l}\mathrm{DG}=128.806798 \mathrm{MW} \\
\text { Ploss }=105.5056 \mathrm{MW}\end{array}$ & 90 & $\begin{array}{l}\mathrm{DG}=0.330903 \mathrm{MW} \\
\text { Ploss }=110.2137 \mathrm{MW}\end{array}$ \\
\hline 12 & $\begin{array}{l}\mathrm{DG}=152.120457 \mathrm{MW} \\
\text { Ploss }=102.8647 \mathrm{MW}\end{array}$ & 51 & $\begin{array}{l}\mathrm{DG}=163.27574 \mathrm{MW} \\
\text { Ploss }=102.8127 \mathrm{MW}\end{array}$ & 91 & $\begin{array}{l}\mathrm{DG}=0.316752 \mathrm{MW} \\
\text { Ploss }=109.6929 \mathrm{MW}\end{array}$ \\
\hline 13 & $\begin{array}{l}\mathrm{DG}=126.151012 \mathrm{MW} \\
\text { Ploss }=105.477 \mathrm{MW}\end{array}$ & 52 & $\begin{array}{l}\mathrm{DG}=136.609037 \mathrm{MW} \\
\text { Ploss }=99.9051 \mathrm{MW}\end{array}$ & 92 & $\begin{array}{l}\mathrm{DG}=2.233726 \mathrm{MW} \\
\text { Ploss }=108.8771 \mathrm{MW}\end{array}$ \\
\hline 14 & $\begin{array}{l}\mathrm{DG}=107.545112 \mathrm{MW} \\
\text { Ploss }=107.204 \mathrm{MW}\end{array}$ & 53 & $\begin{array}{l}\mathrm{DG}=150.923477 \mathrm{MW} \\
\text { Ploss }=105.3903 \mathrm{MW}\end{array}$ & 93 & $\begin{array}{l}\mathrm{DG}=0.366261 \mathrm{MW} \\
\text { Ploss }=111.7052 \mathrm{MW}\end{array}$ \\
\hline 15 & $\begin{array}{l}\mathrm{DG}=211.945829 \mathrm{MW} \\
\text { Ploss }=98.2005 \mathrm{MW}\end{array}$ & 54 & $\begin{array}{l}\mathrm{DG}=298.042439 \mathrm{MW} \\
\text { Ploss }=98.1309 \mathrm{MW}\end{array}$ & 94 & $\begin{array}{l}\mathrm{DG}=27.96989 \mathrm{MW} \\
\text { Ploss }=109.041 \mathrm{MW}\end{array}$ \\
\hline 16 & $\begin{array}{l}\mathrm{DG}=114.670716 \mathrm{MW} \\
\text { Ploss }=104.1251 \mathrm{MW}\end{array}$ & 55 & $\begin{array}{l}\mathrm{DG}=253.003086 \mathrm{MW} \\
\text { Ploss }=95.9371 \mathrm{MW}\end{array}$ & 95 & $\begin{array}{l}\mathrm{DG}=56.557722 \mathrm{MW} \\
\text { Ploss }=112.6194 \mathrm{MW}\end{array}$ \\
\hline 17 & $\begin{array}{l}\mathrm{DG}=215.842192 \mathrm{MW} \\
\text { Ploss }=103.8536 \mathrm{MW}\end{array}$ & 56 & $\begin{array}{l}\mathrm{DG}=300.090378 \mathrm{MW} \\
\text { Ploss }=97.6436 \mathrm{MW}\end{array}$ & 96 & $\begin{array}{l}\mathrm{DG}=75.554861 \mathrm{MW} \\
\text { Ploss }=108.4198 \mathrm{MW}\end{array}$ \\
\hline 18 & $\begin{array}{l}\mathrm{DG}=174.288927 \mathrm{MW} \\
\text { Ploss }=104.1887 \mathrm{MW}\end{array}$ & 57 & $\begin{array}{l}\mathrm{DG}=134.914338 \mathrm{MW} \\
\text { Ploss }=103.1027 \mathrm{MW}\end{array}$ & 97 & $\begin{array}{l}\mathrm{DG}=55.32614 \mathrm{MW} \\
\text { Ploss }=110.343 \mathrm{MW}\end{array}$ \\
\hline 19 & $\begin{array}{l}\mathrm{DG}=208.34031 \mathrm{MW} \\
\text { Ploss }=101.3572 \mathrm{MW}\end{array}$ & 58 & $\begin{array}{l}\mathrm{DG}=151.54828 \mathrm{MW} \\
\text { Ploss }=104.0325 \mathrm{MW}\end{array}$ & 98 & $\begin{array}{l}\mathrm{DG}=43.497228 \mathrm{MW} \\
\text { Ploss }=105.1687 \mathrm{MW}\end{array}$ \\
\hline 20 & $\begin{array}{l}\mathrm{DG}=134.353492 \mathrm{MW} \\
\text { Ploss }=104.3742 \mathrm{MW}\end{array}$ & 59 & $\begin{array}{l}\mathrm{DG}=266.252851 \mathrm{MW} \\
\text { Ploss }=99.2146 \mathrm{MW}\end{array}$ & 99 & $\begin{array}{l}\mathrm{DG}=28.720925 \mathrm{MW} \\
\text { Ploss }=110.7502 \mathrm{MW}\end{array}$ \\
\hline 21 & $\begin{array}{l}\mathrm{DG}=104.928143 \mathrm{MW} \\
\text { Ploss }=107.9008 \mathrm{MW}\end{array}$ & 60 & $\begin{array}{l}\mathrm{DG}=180.029737 \mathrm{MW} \\
\text { Ploss }=109.0783 \mathrm{MW}\end{array}$ & 100 & $\begin{array}{l}\mathrm{DG}=27.109957 \mathrm{MW} \\
\text { Ploss }=112.093 \mathrm{MW}\end{array}$ \\
\hline 22 & $\begin{array}{l}\mathrm{DG}=93.847526 \mathrm{MW} \\
\text { Ploss }=107.3988 \mathrm{MW}\end{array}$ & 61 & $\begin{array}{l}\mathrm{DG}=217.188289 \mathrm{MW} \\
\text { Ploss }=110.277 \mathrm{MW}\end{array}$ & 101 & $\begin{array}{l}\mathrm{DG}=3.152974 \mathrm{MW} \\
\text { Ploss }=109.6081 \mathrm{MW}\end{array}$ \\
\hline 23 & $\begin{array}{l}\mathrm{DG}=112.485273 \mathrm{MW} \\
\text { Ploss }=107.6156 \mathrm{MW}\end{array}$ & 62 & $\begin{array}{l}\mathrm{DG}=148.991549 \mathrm{MW} \\
\text { Ploss }=108.5313 \mathrm{MW}\end{array}$ & 102 & $\begin{array}{l}\mathrm{DG}=0.365233 \mathrm{MW} \\
\text { Ploss }=108.2081 \mathrm{MW}\end{array}$ \\
\hline 24 & $\begin{array}{l}\mathrm{DG}=122.226052 \mathrm{MW} \\
\text { Ploss }=103.1782 \mathrm{MW}\end{array}$ & 63 & $\begin{array}{l}\mathrm{DG}=271.532796 \mathrm{MW} \\
\text { Ploss }=100.6808 \mathrm{MW}\end{array}$ & 103 & $\begin{array}{l}\mathrm{DG}=74.70484 \mathrm{MW} \\
\text { Ploss }=106.3845 \mathrm{MW}\end{array}$ \\
\hline 25 & $\begin{array}{l}\mathrm{DG}=19.467003 \mathrm{MW} \\
\text { Ploss }=105.3804 \mathrm{MW}\end{array}$ & 64 & $\begin{array}{l}\mathrm{DG}=279.219469 \mathrm{MW} \\
\text { Ploss }=106.4706 \mathrm{MW}\end{array}$ & 104 & $\begin{array}{l}\mathrm{DG}=85.591999 \mathrm{MW} \\
\text { Ploss }=107.7868 \mathrm{MW}\end{array}$ \\
\hline 26 & $\begin{array}{l}\mathrm{DG}=45.752497 \mathrm{MW} \\
\text { Ploss }=109.4005 \mathrm{MW}\end{array}$ & 65 & $\begin{array}{l}\mathrm{DG}=239.779886 \mathrm{MW} \\
\text { Ploss }=106.263 \mathrm{MW}\end{array}$ & 105 & $\begin{array}{l}\mathrm{DG}=97.612459 \mathrm{MW} \\
\text { Ploss }=102.0538 \mathrm{MW}\end{array}$ \\
\hline 27 & $\begin{array}{l}\mathrm{DG}=131.689427 \mathrm{MW} \\
\text { Ploss }=104.9029 \mathrm{MW}\end{array}$ & 66 & $\begin{array}{l}\mathrm{DG}=87.578865 \mathrm{MW} \\
\text { Ploss }=109.5058 \mathrm{MW}\end{array}$ & 106 & $\begin{array}{l}\mathrm{DG}=93.781891 \mathrm{MW} \\
\text { Ploss }=109.4429 \mathrm{MW}\end{array}$ \\
\hline
\end{tabular}


Table 22 Optimum solution for the IEEE 118 bus system with DG individually injected at each bus using JAYA algorithm (Continued)

\begin{tabular}{|c|c|c|c|c|c|}
\hline Bus No. & Optimal DG value and Ploss & Bus No. & Optimal DG value and Ploss & Bus No. & Optimal DG value and Ploss \\
\hline 28 & $\begin{array}{l}\mathrm{DG}=124.185209 \mathrm{MW} \\
\text { Ploss }=101.9163 \mathrm{MW}\end{array}$ & 67 & $\begin{array}{l}\mathrm{DG}=74.527333 \mathrm{MW} \\
\text { Ploss }=110.09 \mathrm{MW}\end{array}$ & 107 & $\begin{array}{l}\mathrm{DG}=77.445529 \mathrm{MW} \\
\text { Ploss }=106.6032 \mathrm{MW}\end{array}$ \\
\hline 29 & $\begin{array}{l}\mathrm{DG}=123.581598 \mathrm{MW} \\
\text { Ploss }=104.5658 \mathrm{MW}\end{array}$ & 68 & $\begin{array}{l}\mathrm{DG}=346.448424 \mathrm{MW} \\
\text { Ploss }=104.3674 \mathrm{MW}\end{array}$ & 108 & $\begin{array}{l}\mathrm{DG}=84.482368 \mathrm{MW} \\
\text { Ploss }=110.0862 \mathrm{MW}\end{array}$ \\
\hline 30 & $\begin{array}{l}\mathrm{DG}=202.292999 \mathrm{MW} \\
\text { Ploss }=105.6273 \mathrm{MW}\end{array}$ & 70 & $\begin{array}{l}\mathrm{DG}=215.307567 \mathrm{MW} \\
\text { Ploss }=101.3420 \mathrm{MW}\end{array}$ & 109 & $\begin{array}{l}\mathrm{DG}=73.879514 \mathrm{MW} \\
\text { Ploss }=106.8489 \mathrm{MW}\end{array}$ \\
\hline 31 & $\begin{array}{l}\mathrm{DG}=138.863925 \mathrm{MW} \\
\text { Ploss }=106.1876 \mathrm{MW}\end{array}$ & 71 & $\begin{array}{l}\mathrm{DG}=158.006651 \mathrm{MW} \\
\text { Ploss }=106.6297 \mathrm{MW}\end{array}$ & 110 & $\begin{array}{l}\mathrm{DG}=79.585522 \mathrm{MW} \\
\text { Ploss }=105.6344 \mathrm{MW}\end{array}$ \\
\hline 32 & $\begin{array}{l}\mathrm{DG}=162.13668 \mathrm{MW} \\
\text { Ploss }=102.2741 \mathrm{MW}\end{array}$ & 72 & $\begin{array}{l}\mathrm{DG}=90.968385 \mathrm{MW} \\
\text { Ploss }=105.4622 \mathrm{MW}\end{array}$ & 111 & $\begin{array}{l}\mathrm{DG}=50.012701 \mathrm{MW} \\
\text { Ploss }=104.4401 \mathrm{MW}\end{array}$ \\
\hline 33 & $\begin{array}{l}\mathrm{DG}=145.322161 \mathrm{MW} \\
\text { Ploss }=99.898 \mathrm{MW}\end{array}$ & 73 & $\begin{array}{l}\mathrm{DG}=111.141505 \mathrm{MW} \\
\text { Ploss }=103.8292 \mathrm{MW}\end{array}$ & 112 & $\begin{array}{l}\mathrm{DG}=72.84045 \mathrm{MW} \\
\text { Ploss }=102.0659 \mathrm{MW}\end{array}$ \\
\hline 34 & $\begin{array}{l}\mathrm{DG}=265.489241 \mathrm{MW} \\
\text { Ploss }=97.0874 \mathrm{MW}\end{array}$ & 74 & $\begin{array}{l}\mathrm{DG}=199.515402 \mathrm{MW} \\
\text { Ploss }=100.6688 \mathrm{MW}\end{array}$ & 113 & $\begin{array}{l}\mathrm{DG}=137.217961 \mathrm{MW} \\
\text { Ploss }=106.7375 \mathrm{MW}\end{array}$ \\
\hline 35 & $\begin{array}{l}\mathrm{DG}=212.607941 \mathrm{MW} \\
\text { Ploss }=99.6775 \mathrm{MW}\end{array}$ & 75 & $\begin{array}{l}\mathrm{DG}=257.726006 \mathrm{MW} \\
\text { Ploss }=102.4429 \mathrm{MW}\end{array}$ & 114 & $\begin{array}{l}\mathrm{DG}=128.504699 \mathrm{MW} \\
\text { Ploss }=108.2676 \mathrm{MW}\end{array}$ \\
\hline 36 & $\begin{array}{l}\mathrm{DG}=218.137821 \mathrm{MW} \\
\text { Ploss }=97.5311 \mathrm{MW}\end{array}$ & 76 & $\begin{array}{l}\mathrm{DG}=167.499121 \mathrm{MW} \\
\text { Ploss }=100.5155 \mathrm{MW}\end{array}$ & 115 & $\begin{array}{l}\mathrm{DG}=131.714016 \mathrm{MW} \\
\text { Ploss }=100.0972 \mathrm{MW}\end{array}$ \\
\hline 37 & $\begin{array}{l}\mathrm{DG}=283.577128 \mathrm{MW} \\
\text { Ploss }=103.4836 \mathrm{MW}\end{array}$ & 77 & $\begin{array}{l}\mathrm{DG}=198.98593 \mathrm{MW} \\
\text { Ploss }=106.7565 \mathrm{MW}\end{array}$ & 116 & $\begin{array}{l}\mathrm{DG}=313.132375 \mathrm{MW} \\
\text { Ploss }=108.1146 \mathrm{MW}\end{array}$ \\
\hline 38 & $\begin{array}{l}\mathrm{DG}=324.563925 \mathrm{MW} \\
\text { Ploss }=100.3577 \mathrm{MW}\end{array}$ & 78 & $\begin{array}{l}\mathrm{DG}=166.514813 \mathrm{MW} \\
\text { Ploss }=104.9669 \mathrm{MW}\end{array}$ & 117 & $\begin{array}{l}\mathrm{DG}=86.677252 \mathrm{MW} \\
\text { Ploss }=105.3631 \mathrm{MW}\end{array}$ \\
\hline 39 & $\begin{array}{l}\mathrm{DG}=219.426062 \mathrm{MW} \\
\text { Ploss }=112.9535 \mathrm{MW}\end{array}$ & 79 & $\begin{array}{l}\mathrm{DG}=132.713358 \mathrm{MW} \\
\text { Ploss }=108.0646 \mathrm{MW}\end{array}$ & 118 & $\begin{array}{l}\mathrm{DG}=180.156097 \mathrm{MW} \\
\text { Ploss }=104.5194 \mathrm{MW}\end{array}$ \\
\hline
\end{tabular}

the problems for all the different bus systems. It has successfully obtained the best solution reported in the literature for the above four mentioned IEEE test bus systems for the ORPD problem.

iii. ORPD problem with DG - The JAYA algorithm has provided the best solution to the ORPD problem with DG compared to other algorithms discussed above. It has obtained the best value of DG to be penetrated to the system to minimize the power loss for all the four test bus systems.

iv. Statistical analysis - The statistical analysis of the JAYA algorithm and others was tested on the IEEE 30 bus system, and the results shown in Table 5 demonstrate that the JAYA algorithm is the most

Table 23 Comparison of power loss at the IEEE 118 bus system with different DG power placed at bus no. 40 using the JAYA algorithm

\begin{tabular}{lccc}
\hline DG values (MW) & 234.926829 & 235.926829 (Optimal) & 236.926829 \\
\hline Loss (MW) & 92.1347 & 91.4174 & 91.7172 \\
\hline
\end{tabular}

robust and has a minimum standard deviation compared to the others.

v. Frequency of convergence - This test, which is another method to judge the robustness of the algorithms, was performed for the different algorithms and the results were shown in Table 6 and its significance discussed in Section 4.1.2. Each algorithm was run 50 times and the results show that the JAYA algorithm has obtained the best solution for all 50 times within the range of $4.59-4.60 \mathrm{MW}$, thus proving to be the most robust algorithm.

vi. Convergence speed - The convergence characteristics from the different test cases show that the JAYA algorithm may not be the fastest in terms of computation time, but it provides a good balance between convergence speed and obtaining the best solution.

Thus, these detailed comparisons show the ability of the JAYA algorithm to obtain the best solution to this critical optimization problem and to outperform many other well established techniques in respect of robustness, efficiency and, convergence speed. 
Table 24 Simulation results on the IEEE 118 bus system with DG using different algorithms

\begin{tabular}{lllllllll}
\hline Algorithms & PSO & R-PSO & L-PSO & PSO-CFA & IPSO-SR & FOA & MFOA & JAYA \\
\hline Optimum DG value at bus no. 40 (MW) & 217.915656 & 234.001257 & 233.530451 & 233.862928 & 233.041745 & 353.130050 & 466.923186 & 235.926829 \\
Total $P_{\text {loss }}$ (MW) & 98.2287 & 99.8411 & 97.2316 & 100.6191 & 96.1849 & 147.2732 & 99.5879 & 91.4174 \\
\hline
\end{tabular}

\section{Conclusion}

This paper has shown the effect of the penetration of distributed generation (DG) into the ORPD problem for reducing the transmission line losses for the very first time and has provided a unique contribution in the study of the ORPD problem. A comprehensive study was carried out to locate the optimal bus and determine the corresponding optimal value of DG to be injected to minimize transmission line loss. The results show that power loss is minimized to a large extent when DG is injected into the system, establishing the advantages of the DG penetration in the optimization problem of ORPD. Using four different IEEE standard bus systems, it shows that if the optimal bus and value of DG are known, the power loss can be significantly reduced and system stability improved. This work reveals a new way of analyzing the ORPD problem and offers encouragement towards the utilization of renewable resources. The simulation results confirm that the JAYA algorithm is the best and efficient among the others reported in the literature, in terms of reliability, robustness, consistency, and rate of convergence in solving the ORPD problem for all the case studies. The JAYA algorithm gives consistent results under any condition without violating any equality and inequality constraint.

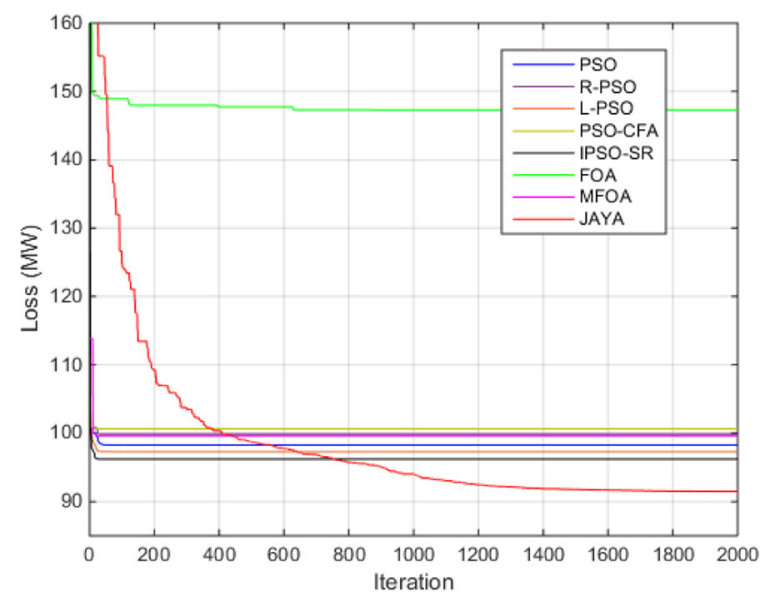

Fig. 13 Convergence characteristics of the algorithms for IEEE 118 bus system with DG

\section{Abbreviations}

$A B C$ : Artificial Bee colony algorithm; $\mathrm{ACO}_{\mathrm{R}}$ : Ant colony optimization algorithm extended to continuous domains; ALC-PSO: Particle Swarm Optimization with Aging Leader and Challengers; ALO: Ant lion optimizer; BA: Bat algorithm; BBDE: Bare-bones DE; BBO: Biogeography-based Optimization; BBPSO: Barebones particle swarm optimization; B-DE: Binary differential evolution; B-DE: Best/1/bin DE; BFO: Bacterial-foraging optimization; BSO: Backtracking search optimizer; CI-PSO: Constant inertia weight conventional PSO; CKHA: Chaotic krill herd algorithm;

CLPSO: Comprehensive Learning PSO; C-PSO: Conventional PSO; CPVEI HBMO: Chaotic Parallel Vector Evaluated Interactive Honey Bee Mating Optimization; CSA: Common Scrambling Algorithm; DDE: Double differential evolution; DE: Differential evolution; DG: Distributed generation; DSA: Digital Signature Algorithm; EMA: Exchange market algorithm; EP: Evolutionary programming; FOA: Fruit Fly optimization algorithm; FPA: Flower Pollination Algorithm; GA: Genetic algorithm; GBTLBO: Gaussian barebones TLBO;

GBWCA: Gravity-Base Objects' Weight Clustering Algorithm;

GSA: Gravitational search algorithm; HBMO: Honey Bee Mating Optimization; HEP: Hybrid evolutionary programming; HSSSA: Hyper-Spherical Search Algorithm; HTS: HIV testing services Algorithm; IALO: Antlion optimization algorithm; ICA: Imperialist competitive algorithm; IPGS-PSO: Improved pseudo gradient search-particle swarm optimization; IPSO-SR: Improved PSO Based on Success Rate; ISSO: Improved social spider optimization algorithm; IWO: Invasive weed optimization; LDI-PSO: Linearly decreasing inertia weight PSO; LPSO: Lévy PSO; MCBOA: Modified colliding bodies optimization algorithm; MDE: Modified differential evolution; MFOA: Modified Fruit Fly optimization algorithm; MGBTLBO: Modified Gaussian barebones TLBO; MICA: Modified imperialist competitive algorithm; MICA-IWO: Hybrid MICAIWO; MOALO: Multi-objective Ant Lion Optimizer; MSFS: Modified stochastic fractal search algorithm; MSSA: Multi-objective Salp Swarm Algorithm; MTLA: Modified teaching learning algorithm; MTLA-DDE: Hybrid MTLA-DDE; NGBWCA: Gaussian bare-bones WCA; OGSA: Opposition-based gravitational search algorithm; OPF: Optimal power flow; ORPD: Optimal Reactive Power Dispatch; PG-PSO: Pseudo-gradient PSO; PGSWT-PSO: Pseudo-gradient Search Particle Swarm Optimization; PSO: Particle Swarm Optimization; PSOCF: Particle Swarm Optimization Collaborative filtering; PSO-CFA: PSO with constriction factor; PSO-ICA: Particle Swarm Optimization Imperialist competitive algorithm hybrid; PSO-TVAC: Particle swarm optimization with time varying acceleration coefficients; PSO-TVAC: Particle Swarm Optimization with Time Varying Acceleration Coefficients; PSO-TVIW: Timevarying inertia weighting strategy based on particle swarm optimization GSA; QOTLBO: Quasi-oppositional teaching learning based optimization; RDE: Rand/1/bin DE; R-PSO: Rapid PSO; RTS: Real-Time Scheduling; SARCGA: Self-adaptive real coded genetic algorithm; SARGA: Using selfadaptive real coded genetic algorithm; SFLA: Shuffled frog leaping algorithm; SGA $\left(F_{f 1}\right)$ : Specialized genetic algorithm using (Ff1); SGA $\left(F_{f_{2}}\right)$ : Specialized genetic algorithm using (Ff2); SOA: Seeker optimization algorithm; SPSOTVAC: Self-organizing hierarchical PSO with Time Varying Acceleration Coefficients; SSA: Salp Swarm Algorithm; SSO: Social spider optimization; SWT-PSO: Stochastic weight trade-off particle swarm optimization; TLA: Teaching learning algorithm; TLBO: Teaching Learning Based Optimization; WCA: Water Cycle Algorithm; WOA: Whale Optimization algorithm

Acknowledgements

Not applicable.

\section{Authors' contributions}

Mr. Tanmay Das carried out basic design, simulation work and prepared draft paper. Dr. Ranjit Roy and Dr. Kamal Krishna Mandal participated in checking simulation work, results \& discussions, sequence of paper and helped to prepare the manuscript. All authors read and approved the final manuscript. 


\section{Funding}

Not applicable.

\section{Availability of data and materials}

The datasets used and analysed during the current study are available from the corresponding author on reasonable request.

\section{Competing interests}

The authors declare that they have no competing interests.

\section{Author details}

'Department of Power Engineering, Jadavpur University, Kolkata, India. 2Department of Electrical Engineering, Chaibasa Engineering College, Chaibasa, Jharkhand, India.

Received: 14 January 2020 Accepted: 1 November 2020 Published online: 01 December 2020

\section{References}

1. Nakawiro, Worawat, István Erlich, and José Luis Rueda. "A novel optimization algorithm for optimal reactive power dispatch: A comparative study." In 2011 4th International Conference on Electric Utility Deregulation and Restructuring and Power Technologies (DRPT), IEEE, pp. 1555-1561, 2011.

2. Abaci, K., \& Yamaçli, V. (2017). Optimal reactive-power dispatch using differential search algorithm. Electrical Engineering: Springer, 99, 213-225.

3. Nayak, M. R., Krishnanand, K. R., \& Rout, P. K. (2011). Optimal reactive power dispatch based on Adaptive Invasive Weed Optimization algorithm. In 2011 International Conference on Energy, Automation and Signal, IEEE, (pp. 1-7).

4. Tanmay, D., \& Ranjit, R. (2018). "a novel algorithm for the optimal reactive power dispatch", 20th National Power Systems Conference (NPSC). IEEE, 1-6.

5. Huang, C.-M., \& Huang, Y.-C. (2012). Combined Differential Evolution Algorithm and Ant System for Optimal Reactive Power Dispatch. In 2nd International Conference on Advances in Energy Engineering (ICAEE), (vol. 14, pp. 1238-1243).

6. Das, T., et al. (2020). Optimal reactive power dispatch incorporating solar power using Jaya algorithm. In K. Maharatna, M. Kanjilal, S. Konar, S. Nandi, \& K. Das (Eds.), Computational advancement in communication circuits and systems, Lecture notes in electrical engineering (vol. 575, pp. 37-48). Singapore: Springer.

7. Weile, D. S., \& Michielssen, E. (1997). Genetic algorithm optimization applied to electromagnetics: A review. IEEE Trans Antennas Propag, 45(3), 343-353.

8. Devaraj, D. (2007). Improved genetic algorithm for multi-objective reactive power dispatch problem. European Transactions on electrical power, 17(6), 569-581.

9. Kennedy, J., \& Eberhart, R. (1995). Particle swarm optimization (PSO). In Proc. IEEE International Conference on Neural Networks, Perth, Australia, (pp. 1942-1948).

10. Wu, Q. H., \& Ma, J. T. (1995). Power system optimal reactive power dispatch using evolutionary programming. IEEE Trans Power Syst, 10(3), 1243-1249.

11. Das, B., \& Patvardhan, C. (2007). A new hybrid evolutionary strategy for reactive power dispatch. In 11th National conference on power systems IISC, Bangalore, (pp. 358-363).

12. Dai, C., ChenW, Z. Y., \& Zhang, X. (2009). Seeker optimization algorithm for optimal reactive power dispatch. IEEE Trans Power Syst, 24(3), 1218-1231.

13. Tripathy, M., \& Mishra, S. (2007). Bacteria foraging-based solution to optimize both real power loss and voltage stability limit. IEEE Trans Power Syst, 22(1), 240-248.

14. Duman, S., Sönmez, Y., \& Güvenç, U. (2012). Yörükeren N (2012) optimal reactive power dispatch using a gravitational search algorithm. IET Gener Transm Distrib, 6(6), 563-576.

15. ElaAAAE,AbidoMA,Spea SR, Differential evolution algorithm for optimal reactive power dispatch. Electr Power Syst Res 81, pp. 458-464, 2011.

16. Ayan, K., \& Kilic, U. (2012). Artificial bee Colony algorithm solution for optimal reactive power flow. App/ Soft Comput, 12, 1477-1482.

17. Medani, B. O., Khaled, S. S., \& Bekrar, A. (2018). Whale optimization algorithm based optimal reactive power dispatch: A case study of the Algerian power system. Electr Power Syst Res, 163, 696-705.

18. Shaheen, A. M., El-Sehiemy, R. A., \& Farrag, S. M. Integrated strategies of backtracking search optimizer for solving reactive power dispatch problem. IEEE Systems Journal, 12(1), 2016, 424-2433.

19. Lenin, K. (2019). Enhanced Red Wolf Optimization Algorithm for Reduction of Real Power Loss. In Smart Intelligent Computing and Applications, (pp. 4551). Singapore: Springer.
20. Nguyen, Thang Trung, and Dieu Ngoc Vo. "Improved social spider optimization algorithm for optimal reactive power dispatch problem with different objectives." Neural Computing and Applications (2019): 1-32.

21. Li, Z., Cao, Y., Le Van Dai, X. Y., \& Nguyen, T. T. (2019). Finding Solutions for Optimal Reactive Power Dispatch Problem by a Novel Improved Antlion Optimization Algorithm. Energies, 12(15), 2968.

22. Mei, R. N. S., Sulaiman, M. H., Daniyal, H., \& Mustaffa, Z. (2018). Application of Moth-flame optimizer and ant lion optimizer to solve optimal reactive power dispatch problems. Journal of Telecommunication, Electronic and Computer Engineering (JTEC), 10(1-2), 105-110.

23. Venkata Rao, R. (2016). Jaya: A simple and new optimization algorithm for solving constrained and unconstrained optimization problems. Int J Ind Eng Comput, 7, 19-34.

24. Ghatak, S. R., Sannigrahi, S., \& Acharjee, P. (2017). Comparative performance analysis of DG and DSTATCOM using improved PSO based on success rate for deregulated environment. IEEE Systems Journal, 12(3), 2791-2802.

25. Ackermann, T., Andersson, G., \& Söder, L. (2001). Distributed generation: A definition. Electr Power Syst Res, 57(3), 195-204.

26. Pepermans, G., Driesen, J., Haeseldonckx, D., Belmans, R., \& D'haeseleer, W. (2005) Distributed generation: Definition, benefits and issues. Energy Policy, 33(6), 787-798.

27. El-Khattam, W. \& Salama, M. M. A. (2004). Distributed generation technologies, definitions and benefits. Electr Power Syst Res, 71(2), 119-128.

28. Dugan, R. C., \& Mcdermott, T. E. (2002). Distributed generation. IEEE Ind App/ Mag, 8(2), 19-25.

29. Jamali, S., Bahmanyar, A., \& Ranjbar, S. (2020). Hybrid classifier for fault location in active distribution networks. Protection and Control of Modern Power Systems, 5(1), 1-9.

30. Singh, M. (2017). Protection coordination in distribution systems with and without distributed energy resources-a review. Protection and Control of Modern Power Systems, 2(1), 2-27.

31. Washington University. https://www2.ee.washington.edu/research/pstca/

32. Ghasemi, M., Ghanbarian, M. M., Ghavidel, S., Rahmani, S., \& Moghaddam, E. M. $(278,2014)$. Modified teaching learning algorithm and double differential evolution algorithm for optimal reactive power dispatch problem: a comparative study. Information Sciences, 231-249.

33. Ghasemi, M., Taghizadeh, M., Ghavidel, S., Aghaei, J., \& Abbasian, A. (2015). Solving optimal reactive power dispatch problem using a novel teachinglearning-based optimization algorithm. Engineering Applications of Artificial Intelligence, 39, 100-108.

34. Ghasemi, M., Ghavidel, S., Ghanbarian, M. M., \& Habibi, A. (2014). A new hybrid algorithm for optimal reactive power dispatch problem with discrete and continuous control variables. App/ Soft Comput, 22, 126-140.

35. Khorsandi, A., Alimardani, A., Vahidi, B., \& Hosseinian, S. H. (2011). Hybrid shuffled frogleaping algorithm and Nelder-Mead simplex search for optima reactive powerdispatch. IET Gener Transm Distrib, 5, 249-256.

36. Villa-Acevedo, W., López-Lezama, J., \& Valencia-Velásquez, J. (2018). A novel constraint handling approach for the optimal reactive power dispatch problem. Energies, 11(9), 2352.

37. Mehdinejad, M. Mohammadi-Ivatloo, B., Dadashzadeh-Bonab, R. \& Zare, K (2016). Solution of optimal reactive power dispatch of power systems using hybrid particle swarm optimization and imperialist competitive algorithms. Int J Electr Power Energy Syst, 83, 104-116.

38. Mouassa, S., \& Bouktir, T. (2019). Multi-objective ant lion optimization algorithm to solve large-scale multi-objective optimal reactive power dispatch problem. COMPEL-The international journal for computation and mathematics in electrical and electronic engineering, 38(1), 304-324.

39. Abaci, K., \& Yamaçli, V. (2017). Optimal reactive-power dispatch using dierential search algorithm. Electr Eng, 99, 213-225.

40. Shaheen, A. M., El-Sehiemy, R. A., \& Farrag, S. M. (2018). Integrated strategies of backtracking search optimizer for solving reactive power dispatch problem. IEEE Syst J, 12, 424-433.

41. Heidari, A. A., Abbaspour, R. A., \& Jordehi, A. R. (2017). Gaussian bare-bones water cycle algorithm for optimal reactive power dispatch in electrical power systems. App/ Soft Comput, 57, 657-671.

42. Anbarasan, P., \& Jayabarathi, T. (2017). Optimal reactive power dispatch problem solved by an improved colliding bodies optimization algorithm, Proceedings of the 2017 IEEE International Conference on Environment and Electrical Engineering, Milan, Italy (pp. 1-6).

43. Mei, R.N.S.; Sulaiman, M.H.; Musta a, Z.; Daniyal, H. Optimal reactive power dispatch solution by loss minimization using moth-flame optimization technique. Appl Soft Comput 2017, 59, 210-222. 
44. Mukheriee, A., \& Mukherjee, V. (2016). Chaotic krill herd algorithm for optimal reactive power dispatch considering FACTS devices. Applied Soft Computing, 44, 163-190.

45. Polprasert, J., Ongsakul, W., \& Dieu, V. N. (2016). Optimal reactive power dispatch using improved pseudo-gradient search particle swarm optimization. Electric Power Components and Systems, 44(5), 518-532.

46. Duman, S., Sonmez, Y., Guvenc, U., \& Yorukeren, N. (2012). Optimal reactive power dispatch using a gravitational search algorithm. IET generation, transmission \& distribution, 6, 563-576.

47. Shaw, B., Mukherjee, V., \& Ghoshal, S. (2014). Solution of reactive power dispatch of power systems by an opposition-based gravitational search algorithm. Int J Electr Power Energy Syst, 55, 29-40.

48. Mahadevan, K., \& Kannan, P. (2010). Comprehensive learning particle swarm optimization for reactive power dispatch. Appl Soft Comput, 10, 641-652

49. Rajan, A., \& Malakar, T. (2016). Exchange market algorithm based optimum reactive power dispatch. Appl Soft Comput, 43, 320-336.

50. Nguyen, T. T., Vo, D. N., Van Tran, H., \& Le Van Dai (2019). Optimal Dispatch of Reactive Power Using Modified Stochastic Fractal Search Algorithm. Complexity, 2019.

51. Subbaraj, P., \& Rajnarayanan, P. N. (2009). Optimal reactive power dispatch using self-adaptive real coded genetic algorithm. Electr Power Syst Res, 79, 374-381.

52. Mukund, R. (2005). Patel. Wind and solar power systems: design, analysis, and operation. CRC press.

\section{Submit your manuscript to a SpringerOpen ${ }^{\circ}$ journal and benefit from:}

- Convenient online submission

Rigorous peer review

- Open access: articles freely available online

High visibility within the field

- Retaining the copyright to your article

Submit your next manuscript at $\boldsymbol{\nabla}$ springeropen.com 